Preprints of the

Max Planck Institute for

Research on Collective Goods

Bonn 2009/13

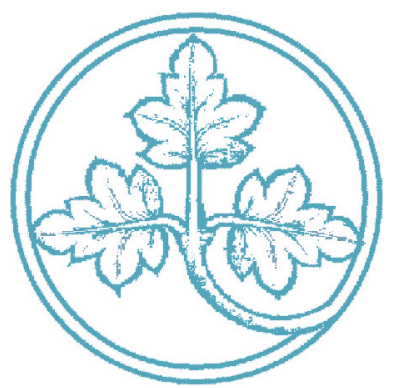

On Competition and the Strategic Management of Intellectual Property in Oligopoly

Jos Jansen

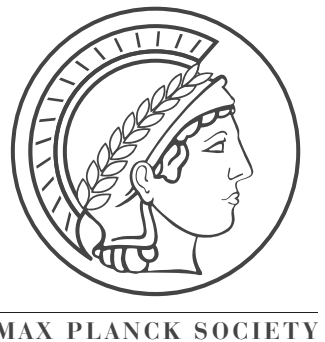




\section{On Competition and the Strategic Management of Intellectual Property in Oligopoly}

Jos Jansen

April 2009 


\title{
On Competition and the Strategic Management of Intellectual Property in Oligopoly*
}

\author{
Jos Jansen \\ Max Planck Institute for Research on Collective Goods ${ }^{\dagger}$
}

April 2009

\begin{abstract}
An innovative firm chooses strategically whether to patent its process innovation or rely on secrecy. By doing so, the firm manages its rival's beliefs about the size of the innovation, and affects the incentives in the product market. Different measures of competitive pressure in the product market have different effects on the equilibrium patenting choices of an innovative firm with unknown costs and probabilistic patent validity. Increasing the number of firms (degree of product substitutability) gives a smaller (greater) patenting incentive. Switching from Bertrand to Cournot competition gives a smaller (greater) patenting incentive if patent protection is weak (strong).
\end{abstract}

Keywords: Bertrand and Cournot competition, oligopoly, product differentiation, entry, asymmetric information, strategic disclosure, stochastic patent, trade secret, process innovation, imitation

JEL Codes: D82, L13, O31, O32

*I thank Vincenzo Denicolò, Christoph Engel, Chiara Fumagalli, Georg von Graevenitz, Dietmar Harhoff, Massimo Motta, Andreas Nicklisch, Jo Seldeslachts, Nicolas Serrano-Velarde, Stefano Trento, Achim Wambach, Philipp Weinschenk, Elmar Wolfstetter, and seminar participants at the Catholic University in Milan, the Robert Schuman Centre for Advanced Studies (Florence), University of Bologna, HCER (Helsinki), University of Cologne, the EARIE conference (Valencia), SFB/TR15 conference (Gummersbach), and Zvi Griliches Summer School in the Economics of Innovation (Barcelona) for their comments. I am grateful for the support of the Social Science Research Center Berlin (WZB) and the European University Institute (Florence), where part of the research for this paper was done. All errors are mine.

†Address: Kurt-Schumacher-Str. 10, D-53113 Bonn, Germany; E-mail <jansen@coll.mpg.de> 


\section{Introduction}

This paper studies the incentives of an innovative firm to patent its process innovation in an oligopoly. A patent discloses the technology to the firm's competitors, but also gives some protection against expropriation of the disclosed technology. However, patents are imperfect, and only give protection with a certain probability (Lemley and Shapiro, 2005). For example, surveys in the 1980s and 1990s of Levin et al. (1987) and Cohen et al. (2000) find that high-level R\&D executives in the US do not consider patent the most effective appropriability mechanism of process innovations. Instead secrecy was often considered as one of the most effective ways to protect process innovations.

I analyze the patenting incentives in a model of asymmetric information about the size of the innovation. In such a setting an innovative firm faces the following trade-off. On the one hand, the potential expropriation of a patented technology yields a more efficient, and more "aggressive" competitor in the product market. This expropriation effect gives the innovative firm a disincentive to apply for a patent. On the other hand, patenting a technology is a way to persuade the competitor of the technology's efficiency. This creates a signaling effect. The innovative firm manages the expectations of its competitor in the product market, and thereby affects his conduct, by patenting certain technologies while keeping other technologies secret. If firms compete in prices, they have an incentive to patent inefficient technologies and keep efficient technologies secret, since this relaxes price competition, and it keeps the cost of expropriation low.

The way in which the market conduct is affected by technology disclosure, depends on the competitive pressure in the industry. I study how the strength of competitive pressure affects the incentive to patent a new production technology. In particular, the competitive pressure is changed in three ways. First, increasing the number of noninnovative firms in the industry increases the intensity of price competition. Second, increasing the degree of product substitutability is an alternative way of increasing the competitive pressure. Firms that produce close substitutes compete more fiercely than firms that produce more differentiated goods. Third, switching from a market where firms strategically set prices (Bertrand competition), to a market where they set output levels (Cournot competition) lowers the competitive pressure for the firms (e.g. see Singh and Vives, 1984).

Different measures of competitive pressure affect the patenting incentives in different ways. Changes of the number of rivals and the product substitutability change 
the relative strength of the signaling effect of disclosure. An increase of the number of non-innovative competitors makes the signalling relatively weaker, and gives a smaller incentive to patent. An increase of the product substitutability has the opposite effect, i.e., it gives a greater incentive to patent.

A change of the mode of competition changes the direction of the signaling effect. A Bertrand oligopolist has an incentive to appear as an inefficient, "soft" competitor in the product market to encourage its competitor (strategic complements). Consequently, in the absence of expropriation the firm has an incentive to disclose inefficient technologies, and keep efficient technologies secret. By contrast, a Cournot oligopolist has an incentive to do the opposite, i.e., only disclose efficient technologies to persuade the competitor that he will face fierce competition in the product market (strategic substitutes). The effect of expropriation is similar under both modes of competition. Clearly, the change of the incentives changes the equilibrium strategies. The aim of the paper is to characterize these changes, and explore their economic consequences.

The analysis may give an explanation for the phenomenon of collective invention (Allen, 1983, and Nuvolari, 2004). For example, profit-maximizing iron producers in 19th century England shared small technology improvements freely with their competitors in the absence of intellectual property right protection. This observation is consistent with the technology sharing equilibrium in my model of Bertrand competition.

The literature on information sharing in oligopoly (e.g. Gal-Or, 1986, and Shapiro, 1986), and particularly recent work on strategic information sharing (Okuno-Fujiwara et al., 1990) has focused on the implications of the signaling effect of information disclosure for product market conduct. Recently, Anton and Yao (2003, 2004), Gill (2008), and Jansen $(2006,2009)$ analyze the trade-off between the expropriation effect and signaling effects in models with strategic substitutability in the production stage. However, as far as I know, this is the first paper to analyze it in a model of Bertrand competition, and to compare the two modes of competition. Changing the mode of competition changes the patenting incentives in an interesting way. Moreover, Anton and Yao (2003, 2004), and Jansen (2006) focus on duopolistic markets with homogeneous goods, while I also consider oligopolistic markets with horizontally differentiated goods here. Finally, whereas Anton and Yao (2003-4) consider divisible innovations, where a firm can choose to patent only an arbitrarily small part of the new technology, I consider indivisible technologies, as in Gill (2008). ${ }^{1}$

\footnotetext{
${ }^{1}$ Whether innovations can be subdivided in small parts depends on the technology. If a process
} 
A second stream of literature, related to this paper, is the recent literature on endogenous knowledge spillovers. For example, De Fraja (1993), Katsoulacos and Ulph (1998), Kamien and Zang (2000), Gersbach and Schmutzler (2003), Fosfuri and Rønde (2004), and Milliou (2009) analyze the choice of technology diffusion in oligopoly models of complete information. Whereas expropriation of technological knowledge affects the spillover choice in these papers, there is no role for signaling. By contrast, signaling plays a central role in my model.

The paper is also related to the extensive literature on the relationship between innovation incentives and competitive pressure (see e.g. Belleflamme and Vergari, 2006, Gilbert, 2006, and Vives, 2008, for overviews). Whereas this literature typically analyzes how competitive pressure affects the incentives to create new knowledge, I study the effects on the incentives to diffuse new knowledge. In other words, my analysis is complementary to this literature.

The paper is organized as follows. The next section describes the model. Section 3 characterizes the equilibrium pricing strategies under patenting and trade secrecy, and the equilibrium patenting strategies. Section 4 discusses the effects of competitive pressure on the incentive to patent an innovation. Section 5 analyzes the robustness of the main results. Finally, section 6 concludes the paper. Appendix A contains the proofs of the paper's main propositions. Appendix B gives more details on the extensions, and makes some observations on the implications for the consumer surplus.

\section{The Model}

Consider $N+1$ risk-neutral firms, firm $I$ and firms $1, . ., N$, producing differentiated goods, with $N \geq 1$. Firm $I$, the innovative firm, obtains a patentable non-drastic process innovation, which yields a production cost $\theta_{I} \in[\underline{\theta}, \bar{\theta}]$, drawn from p.d.f. $f$ : $[\underline{\theta}, \bar{\theta}] \rightarrow \mathbb{R}_{+}$(and corresponding c.d.f. $F:[\underline{\theta}, \bar{\theta}] \rightarrow[0,1]$ ), with $0 \leq \underline{\theta}<\bar{\theta}$. The production $\operatorname{cost} \theta_{I}$ is private information to firm $I .{ }^{2}$ Firms $1, . ., N$, the non-innovative firms, have an inefficient, non-patentable technology, with the production cost $\bar{\theta}$, i.e., $\theta_{1}=\ldots=\theta_{N}=\bar{\theta}^{3}$

After firm $I$ learns its cost, it makes its patent choices. Firm $I$ chooses whether

innovation cannot be broken in small parts, then the full disclosure requirement of a patent only leaves the choice between truthful disclosure or complete concealment of the technology.

${ }^{2}$ This specification allows for uncertainty about the existence of an innovation by assigning a positive probability mass to the atom $\theta_{I}=\bar{\theta}$.

${ }^{3}$ The assumption that there is only one innovative firm is made for simplicity. In section 5 I show that the patenting incentives are similar when there are more innovative firms in the industry. 
to file for a patent and consequently reveal its cost truthfully, $s\left(\theta_{I}\right)=\theta_{I}$, or to keep its cost secret and send the uninformative message $s\left(\theta_{I}\right)=\varnothing$.

Patents are always granted, but their validity is challenged in court. The firm's patent for the new technology is successfully defended in court with probability $\gamma^{P}$, where $0 \leq \gamma^{P} \leq 1$. However, with probability $1-\gamma^{P}$ the patent is invalid, and the firms $1, \ldots, N$ can imitate the patent holder's technology without incurring any cost. ${ }^{4}$ A trade secret remains secret with probability $\gamma^{S}$, but with probability $1-\gamma^{S}$ the secret leaks out to the competitors, enabling them to imitate the leaked technology at no additional cost. To make the problem interesting, I assume that imitation is more likely under patenting than under secrecy $\gamma^{P} \leq \gamma^{S} \leq 1 .^{5}$ For the analysis of patent incentives there is no loss of generality to set $\gamma^{S}=1$ and $\gamma^{P}=\gamma$ with $\gamma \leq 1$. $^{6}$ The parameter $\gamma$ measures the relative protection of patents vis-a-vis secrets.

Finally, after messages are received and the validity of the patent is determined, firms choose the prices of their differentiated goods simultaneously (Bertrand competition). Firm $\ell$ with $\operatorname{cost} \theta_{\ell}$ chooses its price, $p_{\ell} \geq 0$, and earns the profit:

$$
\pi_{\ell}\left(\mathbf{p} ; \theta_{\ell}\right)=D_{\ell}(\mathbf{p})\left(p_{\ell}-\theta_{\ell}\right)
$$

for $\ell \in\{I, 1, \ldots, N\}$. Here $D_{\ell}(\mathbf{p})$ is the demand at prices $\mathbf{p} \equiv\left(p_{I}, p_{1}, . ., p_{N}\right)$ of the representative consumer who enjoys the following utility (e.g. see Dixit, 1979) from consuming the bundle $\mathbf{q} \equiv\left(q_{I}, q_{1}, . ., q_{N}\right)$ for $\ell, k \in\{I, 1, . ., N\}$ :

$$
U(\mathbf{q}) \equiv \omega+\alpha \sum_{\ell} q_{\ell}-\frac{1}{2} \sum_{\ell}\left(q_{\ell}^{2}+\beta q_{\ell} \sum_{k \neq \ell} q_{k}\right) .
$$

Consequently, the inverse demand for the good of firm $\ell$ is linear in quantities, i.e.,

$$
P_{\ell}(\mathbf{q})=\alpha-q_{\ell}-\beta \sum_{k \neq \ell} q_{k}
$$

\footnotetext{
${ }^{4}$ Clearly, the probability of holding an invalid patent can also be interpreted as the probability with which the patent validity is challenged in court, and the defense of the patent fails.

${ }^{5}$ The model with stronger protection of patents than secrets $\left(\gamma^{P}>\gamma^{S}\right)$ would yield the patenting of all technologies in equilibrium, since the signalling benefits of patenting (e.g. Gal-Or, 1986, and Okuno-Fujiwara et al., 1990) would be reinforced by the benefit of less frequent expropriation. The assumption $\gamma^{P} \leq \gamma^{S}$ is consistent with earlier theoretical work (e.g. Anton and Yao, 2003, 2004), and empirical results (e.g. Cohen et al., 2000).

${ }^{6}$ If $\Pi^{P}$ is the profit from a valid patent, $\Pi^{S}$ is the profit from a secret, and $\Pi^{I}$ is the profit after imitation, then the expected profit gain from patenting instead of secrecy is: $\left[\gamma^{P} \Pi^{P}+\left(1-\gamma^{P}\right) \Pi^{I}\right]-$ $\left[\gamma^{S} \Pi^{S}+\left(1-\gamma^{S}\right) \Pi^{I}\right]$. This profit difference equals: $\left[\gamma^{P} \Pi^{P}+\left(\gamma^{S}-\gamma^{P}\right) \Pi^{I}\right]-\gamma^{S} \Pi^{S}$. Clearly, the sign of this net profit is the same as the sign of: $\left[\gamma \Pi^{P}+(1-\gamma) \Pi^{I}\right]-\Pi^{S}$, with $\gamma \equiv \gamma^{P} / \gamma^{S}$.
} 
with $\ell, k \in\{I, 1, . ., N\}$. The direct demand equals:

$$
D_{\ell}(\mathbf{p})=\frac{1}{(1-\beta)(1+N \beta)}\left((1-\beta) \alpha-[1+(N-1) \beta] p_{\ell}+\beta \sum_{k \neq \ell} p_{k}\right)
$$

where $\ell, k \in\{I, 1, . ., N\}$. Firm I's innovation is non-drastic, i.e., I assume that

$$
\alpha \geq 2 \bar{\theta}-\underline{\theta}
$$

Parameter $\beta$ represents the degree of product differentiation, with $0<\beta<1$. For example, if $\beta \rightarrow 0$, the markets for the goods are independent. The greater $\beta$, the more substitutable the firms' goods. I assume that the goods are sufficiently differentiated (i.e., $\beta$ is sufficiently low), such that both firms produce in equilibrium, i.e., $\beta \leq \underline{\beta}$ or:

$$
[2+(2 N-1) \beta](1-\beta)(\alpha-\bar{\theta}) \geq[1+(N-1) \beta] \beta(\bar{\theta}-\underline{\theta})
$$

I solve the game backwards, and restrict the analysis to pure-strategy equilibria.

\section{$3 \quad$ Equilibrium Strategies}

First, I characterize the equilibrium prices for any given patent choice and belief. Second, I derive the equilibrium patenting strategy.

\subsection{Pricing Strategies}

For any given competitors' prices, $\mathbf{p}_{-\ell}$, profit-maximization by firm $\ell$ with marginal cost $\theta_{\ell}$ yields the following best response function (for $\ell, k \in\{I, 1, . ., N\}$ ):

$$
r_{\ell}\left(\mathbf{p}_{-\ell} ; \theta_{\ell}\right)=\frac{1}{2} \theta_{\ell}+\frac{(1-\beta) \alpha+\beta \sum_{k \neq \ell} p_{k}}{2[1+(N-1) \beta]} .
$$

First, I solve the product market stage under complete information. This situation emerges after firm $I$ patents its technology $\theta_{I}$. The cost of non-innovative firms $1, . ., N$ depends on the validity of firm $I$ 's patent. If the patent is valid, then the noninnovative firms cannot adopt the new technology, and $\theta_{1}=\ldots=\theta_{N}=\bar{\theta}$. The best response functions $r_{I}\left(\mathbf{p}_{-I} ; \theta_{I}\right)$ and $r_{n}\left(\mathbf{p}_{-n} ; \bar{\theta}\right)$ for $n=1, . ., N$ then yield the equilibrium price

$$
p_{\ell}^{b}\left(\theta_{\ell}, \sum_{k \neq \ell} \theta_{k}\right)=\theta_{\ell}+m_{\ell}^{b}\left(\theta_{\ell}, \sum_{k \neq \ell} \theta_{k}\right)
$$


for $\theta_{I} \in[\underline{\theta}, \bar{\theta}], \theta_{1}=. .=\theta_{N}=\bar{\theta}$, and $\ell, k \in\{I, 1, . ., N\}$, with the price-cost margin: ${ }^{7}$

$$
m_{\ell}^{b}\left(\theta_{\ell}, \sum_{k \neq \ell} \theta_{k}\right) \equiv \frac{1}{2+(N-2) \beta}\left((1-\beta)\left(\alpha-\theta_{\ell}\right)+\frac{1+(N-1) \beta}{2+(2 N-1) \beta} \beta \sum_{k \neq \ell}\left(\theta_{k}-\theta_{\ell}\right)\right)
$$

If, on the other hand, the patent is invalid, then imitation gives all firms the marginal $\operatorname{cost} \theta_{I}$. In this case, each firm sets the symmetric equilibrium price-cost margin $m_{\ell}^{b}\left(\theta_{I}, N \theta_{I}\right)$ as in (3.3) for $\ell \in\{I, 1, . ., N\}$.

Second, I derive the Bayesian Nash equilibria of the product market stage for any posterior beliefs under incomplete information. After firm $I$ adopts secrecy there is asymmetric information about firm $I$ 's marginal cost $\theta_{I}$, and no imitation is possible. Firm $I$ 's best response function remains $r_{I}\left(\mathbf{p}_{-I} ; \theta_{I}\right)$. Firms $1, . ., N$ update their beliefs about firm I's marginal cost, yielding posterior expected cost $E\left\{\theta_{I} \mid \varnothing\right\}$, and they adopt the best response functions (3.1) for $\ell=1, . ., N$ where $p_{I}$ is replaced by the expected price $E\left\{p_{I}\left(\theta_{I}\right) \mid \varnothing\right\}$. Consequently, the equilibrium price-cost margins are $m_{n}^{b}\left(\bar{\theta}, E\left\{\theta_{I} \mid \varnothing\right\}+(N-1) \bar{\theta}\right)$ for $n=1, . ., N$, and the margin for firm $I$ is:

$$
m_{I}^{B}\left(\theta_{I} ; E\left\{\theta_{I} \mid \varnothing\right\}\right) \equiv m_{I}^{b}\left(\theta_{I}, N \bar{\theta}\right)+\frac{\beta}{2} \cdot \frac{\beta N\left(E\left\{\theta_{I} \mid \varnothing\right\}-\theta_{I}\right)}{[2+(N-2) \beta][2+(2 N-1) \beta]} .
$$

In any case, in equilibrium firm $\ell$ supplies the following output level and earns the following expected profit, respectively (for $r \in\{b, B\}$ and $\ell \in\{I, 1, . ., N\}$ ):

$$
\begin{aligned}
q_{\ell}^{r}(\bullet) & \equiv \frac{1+(N-1) \beta}{(1-\beta)(1+N \beta)} m_{\ell}^{r}(\bullet) \\
\pi_{\ell}^{r}(\bullet) & \equiv \frac{1+(N-1) \beta}{(1-\beta)(1+N \beta)} m_{\ell}^{r}(\bullet)^{2}
\end{aligned}
$$

\subsection{Patenting Strategies}

The innovative firm bases its patenting decision on the comparison of the expected profits from secrecy, and from patenting. The difference between the expected profit from secrecy and patenting is $\pi_{I}^{B}\left(\theta_{I} ; E\left\{\theta_{I} \mid \varnothing\right\}\right)-\gamma \pi_{I}^{b}\left(\theta_{I}, N \bar{\theta}\right)-(1-\gamma) \pi_{I}^{b}\left(\theta_{I}, N \theta_{I}\right)$, which can be written as $\frac{1+(N-1) \beta}{(1-\beta)(1+N \beta)} \Psi^{b}\left(\theta_{I}, E\left\{\theta_{I} \mid \varnothing\right\}\right)$ with:

$$
\Psi^{b}(x, y) \equiv \underbrace{(1-\gamma)\left[m_{I}^{b}(x, N \bar{\theta})^{2}-m_{I}^{b}(x, N x)^{2}\right]}_{\text {expropriation effect }}+\underbrace{\left[m_{I}^{B}(x ; y)^{2}-m_{I}^{b}(x, N \bar{\theta})^{2}\right]}_{\text {signaling effect }}
$$

\footnotetext{
${ }^{7}$ As usual, the equilibrium price is increasing in the costs. The equilibrium price-cost margin is decreasing the own cost, since only part of a firm's cost increase is passed through to consumers.
} 
for $x, y \in[\underline{\theta}, \bar{\theta}]$. The first term of expression (3.7) embodies the expropriation effect. In the event of patent invalidity, which happens with probability $1-\gamma$, the term compares firm $I$ 's profits from a valid patent with the profit from an invalid patent. The second term captures the signaling effect. It compares the firm's profit from secrecy, where firm $n$ expects the cost $y$, with the profit from a valid patent. In other words, while keeping the technology of firm $n$ fixed at the level $\theta_{n}=\bar{\theta}$, the second term measures the profit effect of moving from asymmetric information to complete information.

A technology disclosure by firm $I$ has two effects on competition in the product market. On the one hand, imitation makes firms $1, . ., N$ more "aggressive" competitors, i.e., the firms' best response functions shift inwards (to the left). I call this the expropriation effect. On the other hand, disclosure enables firms $1, . ., N$ to update their beliefs about firm I's product market conduct. This, in turn, may change the non-innovative firms' conduct in the product market, i.e., a non-innovative firm "moves along" its best response curve. This is a signaling effect. The proposition below characterizes the equilibrium patenting rule which results from this trade-off.

Proposition 1 For any $0 \leq \gamma<1$, a critical value $\theta^{b}$ exists, with $\underline{\theta}<\theta^{b}<\bar{\theta}$, such that firm I chooses the following patenting strategy in equilibrium:

$$
s^{b}\left(\theta_{I}\right)=\left\{\begin{array}{l}
\varnothing, \text { if } \underline{\theta} \leq \theta_{I} \leq \theta^{b} \\
\theta_{I}, \text { otherwise. }
\end{array}\right.
$$

In any equilibrium the patenting strategy is as in (3.8) for some $\underline{\theta}<\theta^{b}<\bar{\theta}$. For $\gamma=1$ firm $I$ chooses the patenting strategy $s^{b}\left(\theta_{I}\right)=\theta_{I}$ for any $\theta_{I} \in[\underline{\theta}, \bar{\theta}]$ in equilibrium.

The intuition for this result lies in the analysis of the signaling effect. Since firms compete in prices in the product market, their product market strategies are strategic complements. Consequently, if firm $I$ discloses a technology which is more efficient than expected, then the non-innovative firms adjust their prices downwards (i.e., they "move down" along their best response curves), and become more aggressive competitors. That is, in this case the expropriation effect and the signaling effect reinforce each other, and give a disincentive to apply for a patent. Conversely, disclosure of a technology which is less efficient than expected makes the non-innovative firms less aggressive competitors in the product market (strategic complements). That is, in this case the expropriation and signaling effect conflict, and the patenting incentives are determined by their trade-off. For sufficiently high cost parameters the signaling effect outweighs the expropriation effect, and disclosure softens the conduct of the 
non-innovative firms in the product market. That is, although imitation of a minor innovation makes the firms $1, \ldots, N$ slightly more productive competitors, the firms charge a higher price, since they drastically downgrade their beliefs about the aggressiveness of firm $I$ 's pricing strategy. ${ }^{8}$ As a result, firm $I$ has an incentive to patent such a technology. In short, firm $I$ has an incentive to patent inefficient technologies, and keep efficient technologies secret.

Figure 1 illustrates the equilibrium patenting incentives for a duopolist $(N=1)$ in the absence of patent protection $(\gamma=0)$. The bold lines represent the best response

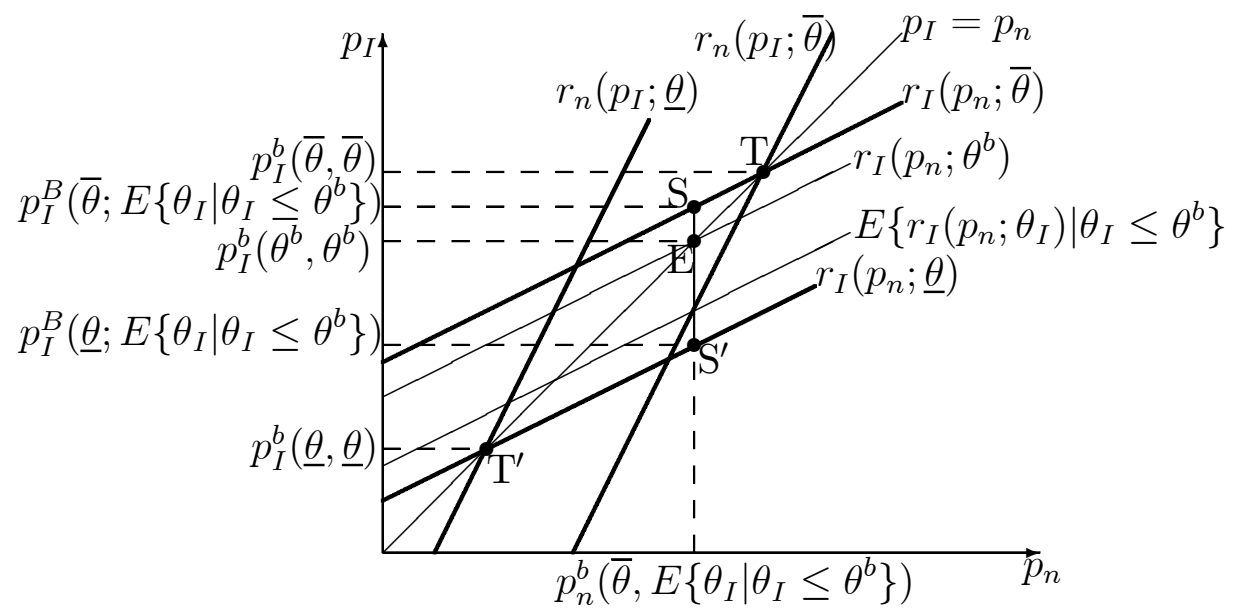

Figure 1: Equilibrium patenting (no protection)

functions of the firms for extreme technologies, i.e., $r_{I}\left(p_{n} ; \underline{\theta}\right)$ and $r_{I}\left(p_{n} ; \bar{\theta}\right)$ for firm $I$, and $r_{n}\left(p_{I} ; \underline{\theta}\right)$ and $r_{n}\left(p_{I} ; \bar{\theta}\right)$ for firm $n$. If firm $I$ shares its technology, the equilibrium prices correspond to a point on the line $\mathrm{T}-\mathrm{T}^{\prime}$. For example, if the firm has technology $\underline{\theta}$ and shares it, the equilibrium prices correspond to point $\mathrm{T}^{\prime}$; if it shares $\theta^{b}$, then the firms reach equilibrium point $\mathrm{E}$; sharing technology $\bar{\theta}$ yields point $\mathrm{T}$. The adoption of secrecy gives the following. Firm $n$ has technology $\bar{\theta}$ and it believes that firm $I$ has a pricing strategy that corresponds to the expected best response $E\left\{r_{I}\left(p_{n} ; \theta_{I}\right) \mid \theta_{I} \leq\right.$ $\left.\theta^{b}\right\}$, which lies between the curves $r_{I}\left(p_{n} ; \theta^{b}\right)$ and $r_{I}\left(p_{n} ; \underline{\theta}\right)$. The point where firm $I^{\prime}$ s expected best response crosses firm $n$ 's best response $r_{n}\left(p_{I} ; \bar{\theta}\right)$ determines firm $n$ 's equilibrium price level, $p_{n}^{b}\left(\bar{\theta}, E\left\{\theta_{I} \mid \theta_{I} \leq \theta^{b}\right\}\right)$. Firm $I$ plays a best response against the price $p_{n}^{b}\left(\bar{\theta}, E\left\{\theta_{I} \mid \theta_{I} \leq \theta^{b}\right\}\right)$, which yields a point along the line S-S'. For example, if the firm keeps technology $\underline{\theta}$ secret, the equilibrium prices correspond to point $\mathrm{S}^{\prime}$; if it

\footnotetext{
${ }^{8}$ For example, for a firm with the least efficient technology $\left(\theta_{I}=\bar{\theta}\right)$ the expropriation effect is absent, while the signalling effect remains, if firms $1, . ., N$ do not hold degenerate beliefs about firm $i$ 's cost (i.e. $E\left\{\theta_{I} \mid \varnothing\right\} \neq \bar{\theta}$ ), and is at its strongest.
} 
hides $\theta^{b}$, then the firms reach equilibrium point $\mathrm{E}$; hiding technology $\bar{\theta}$ yields point $\mathrm{S}$. Comparing the equilibrium prices that firm $I$ sets after technology sharing with the firm's prices under secrecy gives the following. If firm $I$ has a lower cost than $\theta^{b}$, then it can reach a higher equilibrium price by adopting secrecy. For example, the firm that hides technology $\underline{\theta}$ sets price $p_{I}^{B}\left(\underline{\theta} ; E\left\{\theta_{I} \mid \theta_{I} \leq \theta^{b}\right\}\right)$ which is greater than the price it would set if it were to share the technology, $p_{I}^{b}(\underline{\theta}, \underline{\theta})$, since point $\mathrm{S}^{\prime}$ lies above point $\mathrm{T}^{\prime}$. By contrast, if firm $I$ 's technology is less productive than $\theta^{b}$, then technology sharing gives higher equilibrium prices. For example, the least efficient type sets $p_{I}^{b}(\bar{\theta}, \bar{\theta})$ after it discloses, which is greater than its price under secrecy, $p_{I}^{B}\left(\bar{\theta} ; E\left\{\theta_{I} \mid \theta_{I} \leq \theta^{b}\right\}\right)$, since point $\mathrm{T}$ lies above point $\mathrm{S}$. The threshold value for patenting, $\theta^{b}$, is exactly the cost at which firm $I$ is indifferent between patenting and trade secrecy (point E), given beliefs of firm $n$ consistent with patenting strategy $s^{b}$ in (3.8), i.e., $E\left\{\theta_{I} \mid \varnothing\right\}=E\left\{\theta_{I} \mid \theta \leq \theta^{b}\right\}$.

\subsection{Comparative Statics}

For the comparative statics analyses in the next sections I adopt the following definition, since the equilibrium need not be unique. ${ }^{9}$

Definition 1 Define for some parameter $z$ the set of equilibrium thresholds for the patenting strategy (3.8) as $\Theta^{b}(z)$. Then the equilibrium threshold $\theta^{b}$ in (3.8) is increasing (decreasing) in $z$ if for any feasible pair $z^{\prime}$ and $z^{\prime \prime}$ with $z^{\prime}<z^{\prime \prime}$, and any equilibrium threshold $\theta^{b}\left(z^{\prime}\right) \in \Theta^{b}\left(z^{\prime}\right)$, there exists an equilibrium threshold $\theta^{b}\left(z^{\prime \prime}\right) \in \Theta^{b}\left(z^{\prime \prime}\right)$ such that $\theta^{b}\left(z^{\prime}\right)<\theta^{b}\left(z^{\prime \prime}\right)<\bar{\theta}$ (respectively, $\left.\underline{\theta}<\theta^{b}\left(z^{\prime \prime}\right)<\theta^{b}\left(z^{\prime}\right)\right)$.

Using this definition, a change of the patent validity parameter $\gamma$ gives the following comparative statics result.

Proposition 2 For $\gamma<1$, the equilibrium threshold $\theta^{b}$ in (3.8) is decreasing in $\gamma$.

In other words, the stronger the patent protection, the weaker the expropriation effect, and the stronger firm I's incentive to patent the technology. This is intuitive.

The uniform technology distribution (i.e., $F\left(\theta_{I}\right)=\left(\theta_{I}-\underline{\theta}\right) /(\bar{\theta}-\underline{\theta})$ for $\theta_{I} \in[\underline{\theta}, \bar{\theta}]$ ) yields a unique equilibrium. Figure 2 illustrates the proposition for a uniformly distributed technology $\theta_{I}$. The bold, downward-sloping curve sketches the threshold level $\theta^{b}$ in Proposition 1 as a function of the patent validity parameter $\gamma$. Technologies above the curve are patented, while technologies below the curve are kept secret.

\footnotetext{
${ }^{9}$ If the equilibrium is unique, then the definition reduces to the standard monotonicity definition.
} 


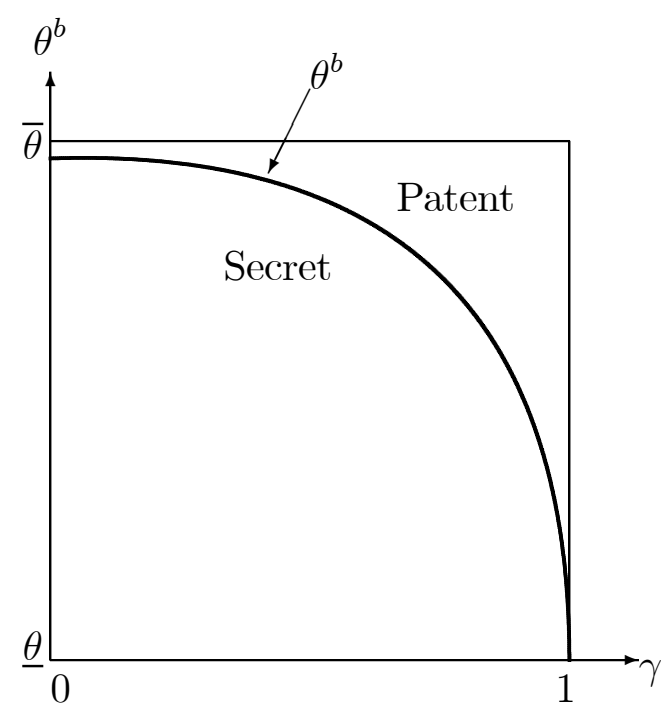

Figure 2: Effect of protection (uniform distribution)

Extreme strengths of intellectual property right give the following incentives. On the one hand, perfect protection (i.e., $\gamma=1$ ) eliminates the expropriation effect of patenting a technology. The remaining signaling effect makes firm $I$ disclose all information in equilibrium, i.e., $\theta^{b}=\underline{\theta}$. Firm $I$ 's incentive to patent any technologies with below-average efficiency levels drives the expected cost level of secret technologies down to the lowest cost level, $\underline{\theta}$. In other words, for $\gamma=1$ the unraveling result applies (Okuno-Fujiwara et al., 1990).

On the other hand, in the absence of intellectual property rights (i.e., $\gamma=0$ ), the innovative firm trades off the expropriation effect against the signaling effect. Interestingly, in spite of the full expropriation of any disclosed technology, the innovative firm still has an incentive to share some technologies with its competitors (i.e., any $\left.\theta_{I}>\theta^{b}\right)$, as is shown in Proposition 1. This results from the firm's incentive to strategically manage its competitors' expectations in the product market. It may explain the phenomenon of collective invention (Allen, 1983), where firms freely share incremental process innovations with their competitors.

A change of the technology distribution function has the following effect:

Proposition 3 Take any two distributions $F$ and $G$ with $E_{F}\left\{\theta_{I} \mid \theta_{I} \leq x\right\} \geq E_{G}\left\{\theta_{I} \mid \theta_{I} \leq\right.$ $x\}$ for all $x \in[\underline{\theta}, \bar{\theta}]$. For any equilibrium threshold $\theta_{F}^{b}$ in (3.8) for distribution $F$, there exists an equilibrium threshold $\theta_{G}^{b}$ in (3.8) for distribution $G$ such that $\underline{\theta}<\theta_{G}^{b} \leq \theta_{F}^{b}$.

Skewing the distribution towards efficient technologies (by moving from $F$ to $G$ ) gives a stronger signaling effect. The disclosure of an inefficient technology by a 
patent creates a more drastic update of the non-innovative firms' beliefs, and thereby a greater price effect. The stronger signaling effect gives a greater incentive to patent technologies.

The condition in Proposition 3 is satisfied if $F$ dominates $G$ in terms of the reverse hazard rate (i.e., $f(\theta) / F(\theta) \geq g(\theta) / G(\theta)$ for all $\theta$ ). For example, the truncated exponential distribution satisfies this property. Assume that the technology $\theta_{I}$ lies in interval $[0, \bar{\theta}]$, and has the distribution $F\left(\theta_{I} ; \lambda\right)=\left(1-e^{-\theta_{I} / \lambda}\right) /\left(1-e^{-\bar{\theta} / \lambda}\right)$. An increase of the hazard rate parameter $\lambda$ increases the conditional expected cost $E\left\{\theta_{I} \mid \theta_{I} \leq x\right\}$ for all $x \in[0, \bar{\theta}] \cdot{ }^{10}$ Then Proposition 3 implies that the equilibrium patenting threshold $\theta^{b}$ is increasing in $\lambda .^{11}$

\section{Competitive Pressure}

In this section I analyze the effects of competitive pressure on the incentives to patent the technology $\theta_{I}$. First, I increase the competitive pressure by increasing the number of non-innovative firms in the industry. Second, I increase the degree of substitutability between products, $\beta$. Finally, I change the mode of competition by switching from competition in prices (Bertrand) to competition in output levels (Cournot).

\subsection{Number of Competitors}

One way of increasing the competitive pressure on the innovative firm is to increase the number of non-innovative firms in the industry, $N$ (Boone, 2000). Increasing $N$ gives the following (using Definition 1).

Proposition 4 If $\gamma=0$ (no protection), then the equilibrium threshold $\theta^{b}$ in (3.8) is increasing in $N$ for any $N \geq 1$.

In other words, in equilibrium the entry of non-innovative firms gives a lower incentive to apply for a patent. For example, the uniform technology distribution gives a unique patenting equilibrium. In the absence of protection the threshold value $\theta^{b}$ for the uniform distribution equals:

$$
\theta_{U}^{b}=\bar{\theta}-\frac{\beta(\bar{\theta}-\underline{\theta})}{4+(4 N-3) \beta}
$$

\footnotetext{
${ }^{10}$ The conditional expected cost equals $E\left\{\theta_{I} \mid \theta_{I} \leq x\right\}=\lambda\left(1-\frac{(x / \lambda) \exp \{-x / \lambda\}}{1-\exp \{-x / \lambda\}}\right)$, and it is straightforward to show that $\partial E\left\{\theta_{I} \mid \theta_{I} \leq x\right\} / \partial \lambda>0$ for all $0<x \leq \bar{\theta}$.

${ }^{11}$ Another non-parametric example that satisfies the proposition's sufficient condition is a setting in which $F$ is convex and $G$ is concave. In that case $E_{G}\left\{\theta_{I} \mid \theta_{I} \leq x\right\} \leq \frac{1}{2} x \leq E_{F}\left\{\theta_{I} \mid \theta_{I} \leq x\right\}$ for all $x$.
} 
Clearly, this value increases in the number of non-innovative firms (i.e., $\partial \theta_{U}^{b} / \partial N>0$ ).

An illustration of this result goes as follows. The best response function $r_{I}\left(\mathbf{p}_{-I} ; \theta_{I}\right)$ in (3.1) captures the pricing strategy of firm $I$. Since the best response is only a function of the cumulative price of the non-innovative firms, the best response can be redefined as $r_{I}\left(P_{N} ; \theta_{I}\right)$ where $P_{N} \equiv \sum_{k=1}^{N} p_{k}$. The system of best response functions $r_{n}\left(\mathbf{p}_{-n} ; \theta_{n}\right)$ in $(3.1)$ for $n=1, \ldots, N$, with $\theta_{1}=\ldots=\theta_{N}$, can be reduced to a single cumulative best response function $N R_{N}\left(p_{I} ; \theta_{n}\right)$. Adding the best response functions of non-innovative firms, and solving for the sum of their prices, $P_{N}$, at any price of firm $I$, and dividing by $N$, gives the cumulative best response per non-innovative firm:

$$
R_{N}\left(p_{I} ; \theta_{n}\right)=\frac{1+(N-1) \beta}{2+(N-1) \beta} \theta_{n}+\frac{(1-\beta) \alpha+\beta p_{I}}{2+(N-1) \beta}
$$

The solution of firm I's best response to the cumulative price per non-innovative firm,

$$
R_{I}\left(\widehat{p}_{N} ; \theta_{I}\right)=\frac{1}{2} \theta_{I}+\frac{(1-\beta) \alpha+N \beta \widehat{p}_{N}}{2[1+(N-1) \beta]}
$$

with $\widehat{p}_{N} \equiv P_{N} / N$, and the cumulative best response per non-innovative firm, $R_{N}\left(p_{I} ; \theta_{n}\right)$, gives the equilibrium prices of the innovative firm and a non-innovative firm. Figure 3 illustrates these best responses for a given belief about firm I's technology, and two values of $N$, i.e., $N^{\prime}$ and $N^{\prime \prime}$ with $N^{\prime \prime}>N^{\prime}$. The thin (bold) curves represent the

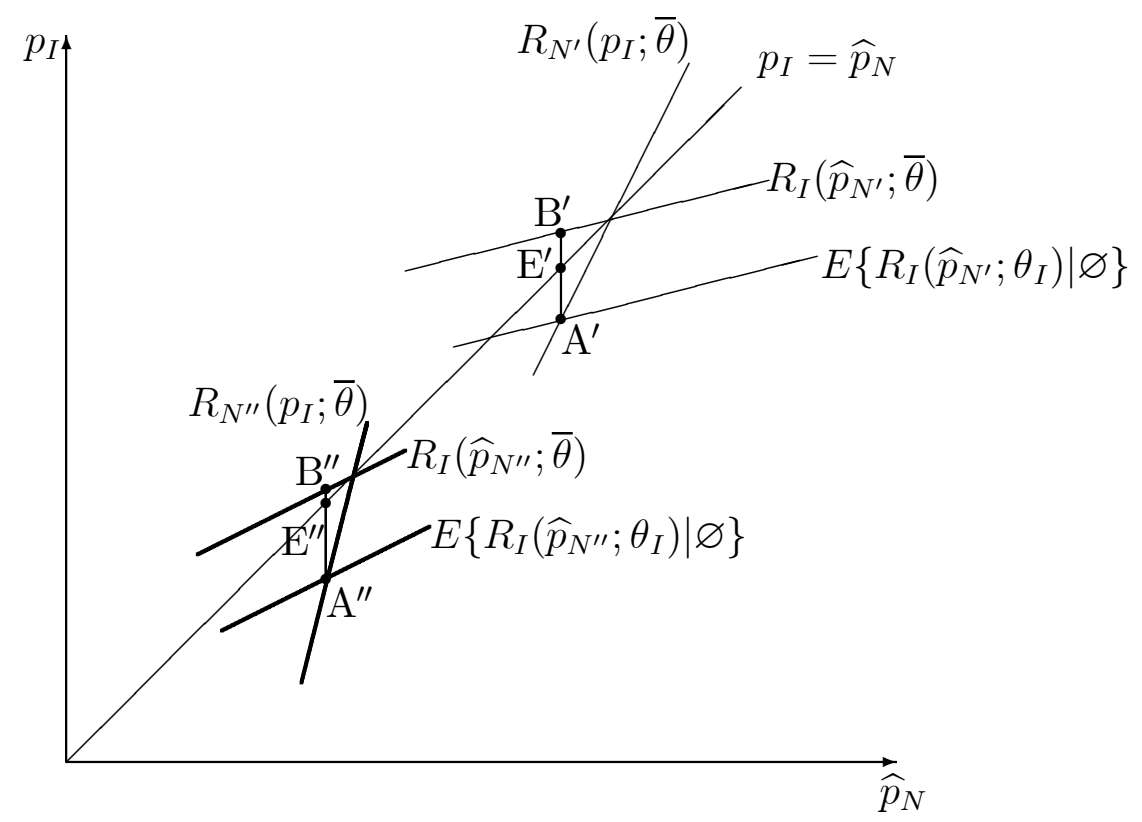

Figure 3: Effects of entry $\left(N^{\prime \prime}>N^{\prime}\right)$

best response curves when there are $N^{\prime}$ (respectively, $N^{\prime \prime}$ ) non-innovative firms. First, 
consider the case in which firm $I$ competes with $N^{\prime}$ non-innovative firms. Analogous to the discussion of Figure 1, if the firm hides a technology of below-average efficiency, then it can reach some price along the line $\mathrm{A}^{\prime}-\mathrm{B}^{\prime}$. If firm $I$ has a technology such that its best response curve runs through point $\mathrm{E}^{\prime}$, then the firm is indifferent between secrecy and technology sharing. The firm prefers to keep more efficient technologies secret, while it shares less efficient technologies. Second, similar incentives emerge in case there are $N^{\prime \prime}$ non-innovative firms. An increase in the number of non-innovative firms (e.g. from $N^{\prime}$ to $\left.N^{\prime \prime}\right)$ makes the innovative firm's best response function $R_{I}\left(\widehat{p}_{N} ; \theta_{I}\right)$ steeper, whereas it makes a non-innovative firm's cumulative best response $R_{N}\left(p_{I} ; \theta_{n}\right)$ less steep, as is illustrated in the figure. ${ }^{12}$ Both effects give a higher cost $\theta_{I}$ at which firm $I$ is indifferent between secrecy and technology sharing, for a given belief. In Figure 3 this is captured by the fact that the distance $\mathrm{A}^{\prime \prime}-\mathrm{E}^{\prime \prime}$ exceeds the distance $\mathrm{A}^{\prime}-\mathrm{E}^{\prime}$, whereas the distance $\mathrm{A}^{\prime \prime}-\mathrm{B}^{\prime \prime}$ equals the distance $\mathrm{A}^{\prime}-\mathrm{B}^{\prime}$ for a given belief about firm I's technology. Therefore, all else equal, firm $I$ has an incentive to keep more technologies secret after the number of non-innovative firms grows.

\subsection{Product Differentiation}

An alternative way of increasing the competitive pressure on the innovative firm is to increase the degree of substitutability between products, $\beta$ (Boone, 2000).

First, assume that the goods are sufficiently differentiated, such that firms choose accommodating pricing strategies, i.e., condition (2.6) holds. An increase of $\beta$ makes the best responses (4.2) and (4.3) steeper in the price. On the one hand, a steeper best response of firm $I,(4.3)$, reduces the incentive to share technologies in the absence of intellectual property protection. The previous subsection illustrates this point. On the other hand, a steeper cumulative best response per non-innovative firm, (4.2), gives a greater incentive to share technologies. The following proposition shows that the latter effect dominates (using Definition 1).

Proposition 5 If $\gamma=0$ (no protection), then the equilibrium threshold $\theta^{b}$ in (3.8) is decreasing in $\beta$ for any $\beta>0$ which satisfy condition (2.6).

For example, in the absence of protection, the uniform technology distribution gives the threshold value $\theta_{U}^{b}$ in (4.1). Clearly, this threshold is decreasing in $\beta$ (i.e., $\left.\partial \theta_{U}^{b} / \partial \beta<0\right)$.

\footnotetext{
${ }^{12} \mathrm{An}$ increase of $N$ also shifts both best response functions inwards (towards the origin), but this does not affect firm $I$ 's incentives to share its technology.
} 
At the extreme where goods approach independence (i.e., $\beta \rightarrow 0$ ), the signaling effect diminishes. The remaining expropriation effect gives firm $I$ a disincentive to patent its technology. In the limit firm $I$ no longer has an incentive to patent any technology, i.e., $\lim _{\beta \rightarrow 0} \theta^{b}=\bar{\theta} \cdot{ }^{13}$ For positive degrees of substitutability the firm has an incentive to patent inefficient technologies in equilibrium (Proposition 1). This suggests that, at least locally (for $\beta$ close to zero), patenting incentives are increasing in the degree of substitutability, i.e., $\lim _{\beta \rightarrow 0} \partial \theta^{b} / \partial \beta<0$. The proposition proves that the threshold $\theta^{b}$ is decreasing in $\beta$ for all parameter values that yield accommodating pricing strategies in the absence of patent protection.

Second, suppose that the goods are close substitutes. With close substitutes, and a sufficiently efficient technology, $\theta_{I}$, firm $I$ has an incentive to set a limit price. A firm that can set a limit price does not have the incentive to patent its innovation. Under secrecy it excludes firm $n$ by setting the limit price. If the firm would patent, then it would have to accommodate firm $n$ with probability $1-\gamma$. An increase of the degree of substitutability, $\beta$, increases the range of technologies for which limit-pricing is feasible. Eventually (i.e., for $\beta$ sufficiently high), the incentive for secrecy grows, and $\partial \theta^{b} / \partial \beta>0$. In the limit for $\beta \rightarrow 1$ (i.e., homogeneous goods) an innovative firm with any technology $\theta_{I}<\bar{\theta}$ can exclude the non-innovative firm by keeping its technology secret, while it risks sharing the market after patenting. ${ }^{14}$ Hence, in the limit firm $I$ chooses full secrecy in equilibrium (i.e., $\lim _{\beta \rightarrow 1} \theta^{b}=\bar{\theta}$ ) to avoid sharing the market with firm $n$.

The description above suggests that there is an inverse U-shaped relation between the degree of product substitutability, and the incentive to patent in equilibrium. In the two extremes, for independent markets and perfect substitutes, the innovative firm relies on full secrecy. Between the two extremes the firm patents inefficient technologies.

\footnotetext{
${ }^{13}$ Clearly, if $\beta=0$, the markets are independent, and firm $I$ is indifferent between patenting and secrecy. As a consequence, any patenting strategy can be sustained as an equilibrium strategy. If $\beta<$ 0 , then the goods are complements. As before, imitation gives the non-innovative firms an incentive to set lower prices. In the case of complementary goods, the competitors' price reduction increases the demand and profit of the innovative firm. In other words, expropriation gives the innovative firm an extra incentive to apply for a patent. Hence, the basic trade-off between expropriation and signalling disappears, and the standard unraveling result applies (i.e., the innovative firm patents all technologies), whenever the goods are complementary.

${ }^{14}$ Clearly, the firm with the worst technology $\left(\theta_{I}=\bar{\theta}\right)$ is indifferent between patenting and secrecy.
} 


\subsection{Mode of Competition}

Finally, the competitive pressure on the innovative firm reduces when the firms switch from competition in prices to competition in quantities (Singh and Vives, 1984).

\subsubsection{Output Strategies}

In case of competition in quantities (Cournot competition), firm $\ell$ with cost $\theta_{\ell}$ chooses its output level, $q_{\ell} \geq 0$, to maximize the profit:

$$
\pi_{\ell}\left(\mathbf{q} ; \theta_{\ell}\right)=\left(P_{\ell}(\mathbf{q})-\theta_{\ell}\right) q_{\ell}
$$

with inverse demand $P_{\ell}(\mathbf{q})$ as in $(2.3)$ for $\ell \in\{I, 1, . ., N\}$.

After firm $I$ patents its technology $\theta_{I}$, the firms set output levels under complete information. If the patent is valid, then firm $\ell$ sets the following output level in equilibrium (for $\theta_{I} \in[\underline{\theta}, \bar{\theta}], \theta_{1}=. .=\theta_{N}=\bar{\theta}$, and $\ell, k \in\{I, 1, . ., N\}$ ):

$$
q_{\ell}^{c}\left(\theta_{\ell}, \sum_{k \neq \ell} \theta_{k}\right) \equiv \frac{1}{2+N \beta}\left(\alpha-\theta_{\ell}+\frac{\beta}{2-\beta} \sum_{k \neq \ell}\left(\theta_{k}-\theta_{\ell}\right)\right) \text {. }
$$

If the patent is invalid, each firm has the marginal cost $\theta_{I}$, and chooses $q_{\ell}^{c}\left(\theta_{I}, N \theta_{I}\right)$ as in (4.5) for $\ell \in\{I, 1, . ., N\}$.

By contrast, if firm $I$ adopts secrecy, the non-innovative firms have incomplete information about the technology $\theta_{I}$. Given posterior expected cost $E\left\{\theta_{I} \mid \varnothing\right\}$, the firms $n=1, . ., N$ and $I$ choose the equilibrium output levels $q_{n}^{c}\left(\bar{\theta}, E\left\{\theta_{I} \mid \varnothing\right\}+(N-1) \bar{\theta}\right)$, and:

$$
q_{I}^{C}\left(\theta_{I} ; E\left\{\theta_{I} \mid \varnothing\right\}\right) \equiv q_{I}^{c}\left(\theta_{I}, N \bar{\theta}\right)+\frac{\beta}{2} \cdot \frac{\beta N\left(\theta_{I}-E\left\{\theta_{I} \mid \varnothing\right\}\right)}{(2+N \beta)(2-\beta)} .
$$

In any case, firm $\ell$ 's profit equals: $\pi_{\ell}^{r}(\bullet)=q_{\ell}^{r}(\bullet)^{2}$, for $\ell \in\{I, 1, \ldots, N\}$ and $r \in\{c, C\}$.

\subsubsection{Patenting Strategies}

The patenting choice of a firm that competes in output levels (strategic substitutes) also trades off the expropriation effect and a signaling effect. For technologies with below-average efficiency levels both effects of patenting are negative. In particular, potential expropriation of the technology makes the rival (firm $n$ ) compete more aggressively. Moreover, the rival updates his beliefs in an unfavorable direction, since he learns that firm $I$ is less efficient (and aggressive) than expected, which makes the rival compete even more aggressively, since the actions are strategic substitutes. In short, the firm has no incentive to patent any inefficient technologies. For technologies 
with an above-average efficiency level the two effects of patenting are in conflict. On the one hand, the expropriation effect still gives firm $I$ an incentive to keep the technology secret. However, on the other hand, now the signaling effect gives an incentive to apply for a patent.

This brief description of the patenting incentives already suggests that the firm's patenting strategies under Cournot competition differ from the patenting strategies under Bertrand competition. Whereas the firm patents only inefficient technologies under Bertrand competition, it has a clear disincentive to do so under Cournot competition. In the remainder of this subsection I give the conditions under which firm $I$ patents efficient technologies. Before stating the proposition, I define the following critical value:

$$
\gamma^{o} \equiv 1-\frac{\beta}{2}\left(\frac{E\left\{\theta_{I}\right\}-\underline{\theta}}{\bar{\theta}-\underline{\theta}}\right) \frac{q_{I}^{c}(\underline{\theta}, N \bar{\theta})+q_{I}^{C}\left(\underline{\theta} ; E\left\{\theta_{I}\right\}\right)}{q_{I}^{c}(\underline{\theta}, N \bar{\theta})+q_{I}^{c}(\underline{\theta}, N \underline{\theta})}
$$

where $0<\gamma^{o}<1$.

Proposition 6 For any $0 \leq \gamma \leq 1$ a critical value $\theta^{c}$ exists, with $\underline{\theta} \leq \theta^{c} \leq \bar{\theta}$, such that firm I chooses the following patenting strategy in equilibrium:

$$
s^{c}\left(\theta_{I}\right)=\left\{\begin{array}{l}
\theta_{I}, \text { if } \underline{\theta} \leq \theta_{I}<\theta^{c} \\
\varnothing, \text { otherwise. }
\end{array}\right.
$$

In particular, (a) an equilibrium exists in which firm I patents all technologies (i.e., $\left.\theta^{c}=\bar{\theta}\right)$ if and only if $\gamma \geq 1-\frac{1}{2} \beta$; (b) an equilibrium exists in which firm I keeps any technology secret (i.e., $\theta^{c}=\underline{\theta}$ ) if and only if $\gamma \leq \gamma^{o}$, with $\gamma^{o}$ as in (4.7). (c) if $\gamma^{o}<1-\frac{1}{4} \beta$, then for any $\gamma^{o}<\gamma<1-\frac{1}{4} \beta$ an equilibrium exists in which firm $I$ chooses strategy (4.8) for some $\theta^{c}$ with $\underline{\theta}<\theta^{c}<\bar{\theta}$. Moreover, for any equilibrium the patenting strategy is as in (4.8) for some $\underline{\theta} \leq \theta^{c} \leq \bar{\theta}$.

These equilibrium strategies differ from the strategies in Anton and Yao (2003, 2004). The innovative firm in Anton and Yao patents small innovations to a greater extent than big innovations, whereas here the reverse tends to happen. That is, the assumption of indivisibility of the innovation has a non-trivial effect on the strategies that the innovative firm chooses in equilibrium.

For those parameter values where the equilibrium patenting rule of Proposition 6 (c) exists, I obtain the following comparative statics result (using Definition 1). ${ }^{15}$

\footnotetext{
${ }^{15}$ The proof of this proposition is similar to the proof of proposition 2 , and is therefore ommitted.
} 
Proposition 7 For any $\gamma^{o}<\gamma<1-\frac{1}{4} \beta$, the equilibrium threshold $\theta^{c}$ in Proposition 6 (c) is increasing in $\gamma$.

The comparison between critical value $\gamma^{o}$, on the one hand, and the values $1-\frac{1}{2} \beta$ and $1-\frac{1}{4} \beta$, on the other, depends on the size of the average technology, $E\left\{\theta_{I}\right\}$. In particular, $\gamma^{o}$ is decreasing in the average technology $E\left\{\theta_{I}\right\}$, and three situations can emerge. These cases are illustrated for $\beta=1$ in Figure 4 . The abbreviations FP, FS,

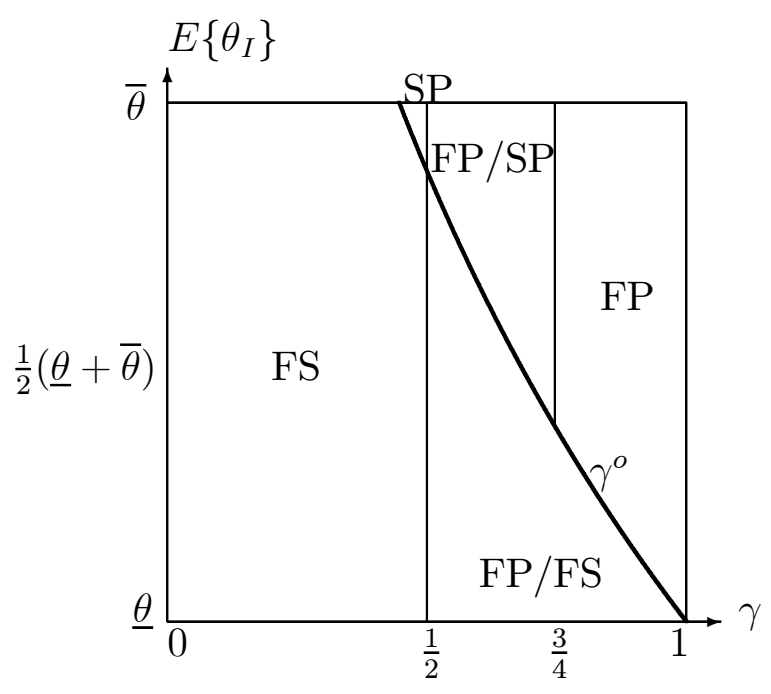

Figure 4: Comparative statics (Cournot competition)

and SP stand for full patenting, full secrecy, and selective patenting, respectively.

An increase of the protection parameter $\gamma$ reduces the strength of the expropriation effect, and gives a greater incentive to patent. An increase of the average technology $E\left\{\theta_{I}\right\}$ increases the strength of the signaling effect (since the disclosure of an efficient technology results in a more drastic update of beliefs), and increases the incentive to patent.

First, if $E\left\{\theta_{I}\right\}$ is sufficiently small (i.e., the technology distribution is skewed towards efficient technologies), then $\gamma^{o}>1-\frac{1}{4} \beta$. In this case there is a range of patent validity probabilities (i.e., for $1-\frac{1}{2} \beta \leq \gamma \leq \gamma^{o}$ ) where equilibrium with full patenting (part a), and the equilibrium with full secrecy (part b) coexist. However, the sufficient condition of part (c) is violated. Hence, an equilibrium where firm $I$ patents only efficient technologies may not exist.

Second, if $E\left\{\theta_{I}\right\}$ is close enough to $\frac{1}{2}(\underline{\theta}+\bar{\theta})$ (e.g. the technology density $f$ is symmetric on the interval $[\underline{\theta}, \bar{\theta}])$, then $1-\frac{1}{2} \beta<\gamma^{o}<1-\frac{1}{4} \beta$. This implies that the range of patent validity probabilities $\left[1-\frac{1}{2} \beta, \gamma^{o}\right]$ exists, where both equilibria with full 
patenting and full secrecy exist. Moreover, now there is a non-empty range of validity probabilities where firm $I$ patents only the most efficient technologies in equilibrium (part c). In this range also the equilibrium with full patenting exists.

Finally, if $E\left\{\theta_{I}\right\}$ is sufficiently large (i.e., the technology distribution is skewed towards inefficient technologies), then $\gamma^{o}<1-\frac{1}{2} \beta$. Again, an equilibrium exists in which only the most efficient technologies are patented for the non-empty parameter range $\left[\gamma^{o}, 1-\frac{1}{4} \beta\right]$ (part c). On the subset $\left[1-\frac{1}{2} \beta, 1-\frac{1}{4} \beta\right]$ of this range there is also an equilibrium in which firm $I$ patents all technologies (part a). Furthermore, there are no longer parameter values where the full patenting equilibrium and the full secrecy equilibrium coexist.

\subsubsection{Technology Diffusion}

The comparison of equilibrium patenting strategies of Propositions 1 and 6 depends on the strength of intellectual property right protection $(\gamma)$. In particular, for sufficiently weak patent protection (e.g. $\gamma \leq \min \left\{1-\frac{1}{2} \beta, \gamma^{o}\right\}$ ) an innovative firm patents more technologies under Bertrand than under Cournot. For these parameter values a firm adopts full secrecy under Cournot competition, while it adopts a selective patenting strategy, where the worst technologies are patented, under Bertrand competition. In other words, there is a greater diffusion of technology under Bertrand competition with weak protection.

If, however, protection is sufficiently strong, but imperfect (e.g. $\max \left\{1-\frac{1}{4} \beta, \gamma^{o}\right\} \leq$ $\gamma<1$ ), then an innovative firm patents more technologies under Cournot competition than under Bertrand competition. Whereas firm $I$ patents any technology (full patenting) for marginally weaker than perfect patent protection under Cournot competition, it keeps the most efficient technologies secret under Bertrand competition. That is, the technology diffusion is greater under Cournot competition when patent protection is strong. In section 6 I briefly discuss the implications of this observation for the expected consumer surplus.

\section{Discussion}

In this section I discuss the robustness of the basic results. First, I adopt different demand functions. Second, I reverse the game's timing. Finally, I extend the model by allowing both firms to be innovative. 


\subsection{Demand}

The model uses the linear demand function of Dixit (1979). This demand function is easy, and it is frequently used in the literature. One property of this demand function is that the size of the market changes by changing the parameters $\beta$ and $N$. An alternative linear demand function, which does not have this property, can be derived from the following utility function (Shapley and Shubik, 1969):

$$
U(\mathbf{q})=\omega+a \sum_{\ell} q_{\ell}-\frac{N+1}{2(1+b)}\left(\sum_{\ell} q_{\ell}^{2}+\frac{b}{N+1}\left[\sum_{k} q_{k}\right]^{2}\right)
$$

for $\ell, k \in\{I, 1, . ., N\}$ and $a>b>0$, which gives the direct demand function

$$
D_{\ell}(\mathbf{p})=\frac{1}{N+1}\left(a-(1+b) p_{\ell}+\frac{b}{N+1} \sum_{k} p_{k}\right)
$$

The parameter $b$ represents the degree of substitutability. It is well-known that for this demand function changes of $b$ and $N$ leave the size of the market unaffected.

As it turns out, the results of sections 3 and 4 are robust with respect to a change from demand function (2.4) to (5.2). A change in the market size yields a change in price levels. However, the patenting incentives are determined by price differences (between prices under patenting and prices under secrecy), not the price levels. This explains why the analysis of the incentives in markets with the demand function (5.2) gives results that are qualitatively identical to those of Propositions 1-5 (for further details, see Appendix B).

\subsection{Timing}

The model assumes that the firms choose their prices after the patent validity is determined. This assumption has no effect on the qualitative results.

Consider the model where the patent validity is determined after the firms set prices. In the subgame that starts after the innovative firm patents its technology, the non-innovative firms choose prices that maximize their expected profits $\pi_{n}(\mathbf{p} ; \gamma)=$ $D_{n}(\mathbf{p})\left[p_{n}-\gamma \bar{\theta}-(1-\gamma) \theta_{I}\right]$ for $n \in\{1, . ., N\}$. This gives the equilibrium price-cost margins $m_{I}^{b}\left(\theta_{I}, N\left[\gamma \bar{\theta}+(1-\gamma) \theta_{I}\right]\right)$ and $m_{n}^{b}\left(\gamma \bar{\theta}+(1-\gamma) \theta_{I}, \theta_{I}+(N-1)\left[\gamma \bar{\theta}+(1-\gamma) \theta_{I}\right]\right)$ for $n \in\{1, \ldots, N\}$, with $m_{\ell}^{b}$ as in (3.3). Firm $I$ 's expected profit gain from secrecy can be written as $\frac{1+(N-1) \beta}{(1-\beta)(1+N \beta)} \Psi^{T}\left(\theta_{I}, E\left\{\theta_{I} \mid \varnothing\right\}\right)$, where

$$
\Psi^{T}(x, y) \equiv m_{I}^{B}(x ; y)^{2}-m_{I}^{b}(x, N[\gamma \bar{\theta}+(1-\gamma) x])^{2} .
$$


This function has the same properties as the function $\Psi^{b}$ in (3.7), and therefore Propositions 1-5 also hold for the model with a reversed timing (see Appendix B for further details).

\subsection{Two-Sided Asymmetric Information}

In this section I extend the model by allowing all firms to be innovative. In particular, there are two innovative firms, $I_{1}$ and $I_{2}$, and no non-innovative firms $(N=0)$. At the beginning of the game each firm receives a draw from the interval $[\underline{\theta}, \bar{\theta}]$. Firm $\ell$ 's technology $\theta_{\ell}$ has the distribution $F_{\ell}:[\underline{\theta}, \bar{\theta}] \rightarrow[0,1]$ with $\ell \in\left\{I_{1}, I_{2}\right\}$. The draws $\theta_{I_{1}}$ and $\theta_{I_{2}}$ are independent. Subsequently, the firms choose simultaneously whether to patent the innovation or keep it secret. To simplify the analysis, I assume that patents are invalid, i.e., $\gamma=0$, and conditions (2.5) and (2.6) hold.

The pricing strategies in the models of one-sided and two-sided asymmetric information are similar. Yet two differences are noteworthy. First, a firm with access to both technologies adopts the most productive technology, $\min \left\{\theta_{I_{1}}, \theta_{I_{2}}\right\}$, which could be its own or its competitor's technology. By contrast, in the model with one-sided asymmetric information a non-innovative firm always adopts the technology of the innovative firm, if it has access to this technology. Second, there are different contingencies in the model of two-sided asymmetric information. Now two firms choose whether to share technology or keep it secret. For further details I refer to Appendix B.

The following proposition shows that the equilibrium technology sharing strategies in the models with one-sided and two-sided asymmetric information are similar (see Appendix B).

Proposition 8 If $\gamma=0$, then in any equilibrium, and for any $i \in\left\{I_{1}, I_{2}\right\}$, firm $i$ chooses the patenting rule (3.8) with $\theta^{b}$ replaced by $\theta_{i}^{b}$ for some $\underline{\theta}<\theta_{i}^{b}<\bar{\theta}$.

A firm's technology sharing strategy trades off an expropriation effect against a signaling effect. Even though I assume in this section that patents are invalid $(\gamma=0)$, it is uncertain whether a shared technology will be adopted or not, since this depends on the relative efficiency of two technology draws. Whereas in the model with one-sided asymmetric information the probability of imitation was exogenously fixed, here it depends on the size of the innovation, and the technology distribution of the competitor. In spite of this difference, the firms' incentives to share technologies are similar to the incentives with one-sided asymmetric information. 


\section{Conclusion}

In this paper I analyzed the effects of probabilistic patent validity on strategic patent choices in an oligopoly with asymmetric information, and differentiated goods. Bertrand competitors choose selective patenting strategies where the worst technologies are patented, while the best technologies are kept secret.

Different measures of competitive pressure have different effects on the incentives to patent a process innovation. Whereas an increase in the degree of substitutability increases the patenting incentives of firms that use accommodating pricing strategies, an increase in the number of firms has the opposite effect. Therefore, an increase in the number of non-innovative firms has two conflicting effect on the expected consumer surplus. On the one hand, it increases the expected consumer surplus for a given level of technology diffusion. This is a direct effect. On the other hand, it reduces the expected surplus through a reduction in the diffusion of technology. This is an indirect effect. That is, the strategic management of intellectual property reduces the surplus gain from entry of non-innovative firms. This may have implications for the optimal economic policy towards entry in innovative industries with weak intellectual property right protection.

Changing the mode of product market competition has yet different effects. If the patent protection is weak, then an innovative firm patents more technologies under Bertrand competition than under Cournot competition. For sufficiently weak protection of intellectual property a firm adopts full secrecy under Cournot competition, while it adopts a selective patenting strategy under Bertrand competition. In this case, the bigger diffusion of technology increases the expected consumer surplus under Bertrand competition, which widens the surplus gap between Bertrand and Cournot competition.

If, however, protection is sufficiently strong, but imperfect, then an innovative firm patents more technologies under Cournot competition than under Bertrand competition. Whereas a Cournot competitor patents any innovation (due to an unraveling result), a Bertrand competitor resorts to a selective patenting strategy. In this case the greater technology diffusion under Cournot competition increases the expected consumer surplus under Cournot competition, and reduces the surplus gap between Bertrand and Cournot competition. In fact, there are circumstances in which the typical consumer surplus ranking is reversed.

For example, if goods are perfect substitutes, then a Bertrand competitor has no incentive to patent its technology, whereas a Cournot competitor patents all technolo- 
gies, if patent protection is sufficiently strong. In this case, the following properties are favorable for obtaining a higher expected consumer surplus under Cournot competition than under Bertrand competition. First, an efficient average technology and relatively low levels of patent protection give a high expected knowledge spillover under Cournot competition. The high level of expected technology diffusion increases the expected consumer surplus under Cournot competition. Second, a low demand intercept keeps the price low under Cournot competition, while it does not affect the price under Bertrand competition. Further, a high technology variance is also favorable for the reversal of the surplus ranking, since it creates a high output variance under Cournot competition, which increases the expected consumer surplus. For more details and a formal proof of this observation, see Appendix B.

Finally, the paper's results may also have implications for patent policy. An increase of the patent protection gives the following trade-off for consumers. On the one hand, an increase of the protection reduces the likelihood of expropriation of patented technologies. In other words, welfare-enhancing technology transfers from an innovative firm to non-innovative firms become less likely. On the other hand, increasing the probability of patent validity has an indirect effect through a change of the equilibrium patenting strategy. Increasing the probability of validity implies that more technologies are patented (i.e., $\theta^{b}$ decreases). First, this increases the expected consumer surplus at the margin, since it replaces the expected surplus under secrecy by the expected surplus under patenting. Second, reducing $\theta^{b}$ changes the equilibrium beliefs of non-innovative firms after the adoption of secrecy. In particular, after a reduction of $\theta^{b}$ the firm expects a more efficient competitor in the product market, which reduces equilibrium prices under secrecy. Both indirect effects are positive. Whereas Appendix B contains some preliminary results on the consumer surplus, a more careful analysis awaits future research. 


\section{Appendix}

\section{A Proofs of Propositions}

\section{Proof of Proposition 1}

Using (3.6), firm $I$ patents technology $\theta_{I}$ if:

$$
\gamma m_{I}^{b}\left(\theta_{I}, N \bar{\theta}\right)^{2}+(1-\gamma) m_{I}^{b}\left(\theta_{I}, N \theta_{I}\right)^{2} \geq m_{I}^{B}\left(\theta_{I} ; E\left\{\theta_{I} \mid \varnothing\right\}\right)^{2}
$$

This inequality is equivalent to $\Psi^{b}\left(\theta_{I}, E\left\{\theta_{I} \mid \varnothing\right\}\right) \leq 0$, with $\Psi^{b}$ as defined in (3.7). Notice that $\Psi^{b}(x, y)$ is strictly convex in $x$ :

$$
\begin{aligned}
\frac{\partial^{2} \Psi^{b}}{\partial x^{2}}= & (1-\gamma) \frac{d\left[m_{I}^{b}(x, N \bar{\theta})-m_{I}^{b}(x, N x)\right]}{d x}\left[\frac{\partial m_{I}^{b}(x, N \bar{\theta})}{\partial x}+\frac{d m_{I}^{b}(x, N x)}{d x}\right] \\
& +\frac{\partial\left[m_{I}^{B}(x ; y)-m_{I}^{b}(x, N \bar{\theta})\right]}{\partial x}\left[\frac{\partial m_{I}^{B}(x ; y)}{\partial x}+\frac{\partial m_{I}^{b}(x, N \bar{\theta})}{\partial x}\right] \\
> & 0
\end{aligned}
$$

for any $x, y \in[\underline{\theta}, \bar{\theta}]$ and $0 \leq \gamma<1$, since all (partial) derivatives are negative. The evaluation of $\Psi^{b}$ for extreme values of $x$ and $\gamma<1$ yields the following. $\Psi^{b}(\underline{\theta}, y)>0$ for any $y \in[\underline{\theta}, \bar{\theta}]$. Consequently (due to continuity), the posterior expected cost $y$ consistent with the equilibrium patenting strategy must be strictly below $\bar{\theta}$. If $y<\bar{\theta}$, then $\Psi^{b}(\bar{\theta}, y)<0$. The inequality $\Psi^{b}(\bar{\theta}, y)<0<\Psi^{b}(\underline{\theta}, y)$ for $y<\bar{\theta}$ in combination with the convexity of $\Psi^{b}$ in $\theta_{I}$ yields the observation that any equilibrium patenting rule must be as in (3.8) for some $\underline{\theta} \leq \theta^{b} \leq \bar{\theta}$. Posterior beliefs consistent with this rule yield $E\left\{\theta_{I} \mid \varnothing\right\}=E\left\{\theta_{I} \mid \theta_{I} \leq \theta^{b}\right\}$. The equilibrium threshold value $\theta^{b}$ is the root of:

$$
\widetilde{\Psi}^{b}(x) \equiv \Psi^{b}\left(x, E\left\{\theta_{I} \mid \theta_{I} \leq x\right\}\right)
$$

Clearly, $\widetilde{\Psi}^{b}(\underline{\theta})=\Psi^{b}(\underline{\theta}, \underline{\theta})>0$ for any $\gamma<1$, and $\widetilde{\Psi}^{b}(\bar{\theta})=\Psi^{b}\left(\bar{\theta}, E\left\{\theta_{I}\right\}\right)<0$. The intermediate value theorem implies that for any $\gamma<1$ a $\theta^{b}$ exists, with $\underline{\theta}<\theta^{b}<\bar{\theta}$, such that $\widetilde{\Psi}^{b}\left(\theta^{b}\right)=0$.

If $\gamma=1$, then $\Psi^{b}(x, y)=0$ iff $x=y$, and $\Psi^{b}(x, y)<0$ iff $x>y$. Clearly, the only possible equilibrium is $(3.8)$ with $\theta^{b}=\underline{\theta} .^{16}$

\footnotetext{
${ }^{16}$ Any interior $\theta^{b}$ (i.e. $\underline{\theta}<\theta^{b}<\bar{\theta}$ ) cannot emerge in equilibrium, since a root of $\widetilde{\Psi}^{b}$ would require that $E\left\{\theta_{I} \mid \theta_{I} \leq \theta^{b}\right\}=\theta^{b}$, which is impossible for non-degenerate p.d.f.-s. Also $\theta^{b}=\bar{\theta}$ cannot emerge in equilibrium, since $\Psi^{b}\left(x ; E\left\{\theta_{I}\right\}\right)<0$ for any $x>E\left\{\theta_{I}\right\}$.
} 


\section{Proof of Proposition 2}

Take any pair $\gamma^{\prime}$ and $\gamma^{\prime \prime}$, with $0 \leq \gamma^{\prime}<\gamma^{\prime \prime}<1$. Denote the function $\widetilde{\Psi}^{b}$ in (A.1) as $\widetilde{\Psi}^{b}(x ; \gamma)$ for any $0 \leq \gamma<1$. Moreover, for all $\underline{\theta} \leq x<\bar{\theta}$ :

$$
\widetilde{\Psi}^{b}\left(x ; \gamma^{\prime \prime}\right)-\widetilde{\Psi}^{b}\left(x ; \gamma^{\prime}\right)=\left(\gamma^{\prime}-\gamma^{\prime \prime}\right)\left[m_{I}^{b}(x, N \bar{\theta})^{2}-m_{I}^{b}(x, N x)^{2}\right]<0
$$

Define $\theta^{b}(\gamma)$ such that: $\widetilde{\Psi}^{b}\left(\theta^{b}(\gamma) ; \gamma\right)=0$, where $\underline{\theta}<\theta^{b}(\gamma)<\bar{\theta}$ for any $0 \leq \gamma<1$ (see proposition 1). Now (A.2), together with $\theta^{b}(\gamma)<\bar{\theta}$ for $\gamma \in\left\{\gamma^{\prime}, \gamma^{\prime \prime}\right\}$, implies that:

$$
\widetilde{\Psi}^{b}\left(\theta^{b}\left(\gamma^{\prime}\right) ; \gamma^{\prime}\right)=0>\widetilde{\Psi}^{b}\left(\theta^{b}\left(\gamma^{\prime}\right) ; \gamma^{\prime \prime}\right)
$$

Furthermore, $\widetilde{\Psi}^{b}\left(\underline{\theta} ; \gamma^{\prime \prime}\right)>0$, since $\gamma^{\prime \prime}<1$. The intermediate value theorem implies that a $\theta^{b}\left(\gamma^{\prime \prime}\right)$ exists, with $\underline{\theta}<\theta^{b}\left(\gamma^{\prime \prime}\right)<\theta^{b}\left(\gamma^{\prime}\right)$, such that $\widetilde{\Psi}^{b}\left(\theta^{b}\left(\gamma^{\prime \prime}\right) ; \gamma^{\prime \prime}\right)=0$, since $\widetilde{\Psi}^{b}(x ; \gamma)$ is continuous in $x$, and $\widetilde{\Psi}^{b}\left(\theta^{b}\left(\gamma^{\prime}\right) ; \gamma^{\prime \prime}\right)<0<\widetilde{\Psi}^{b}\left(\underline{\theta} ; \gamma^{\prime \prime}\right)$.

\section{Proof of Proposition 3}

This proof is analogous to the proof of proposition 2. Take any pair of c.d.f.-s $F$ and $G$, with $E_{F}\left\{\theta_{I} \mid \theta_{I} \leq x\right\} \geq E_{G}\left\{\theta_{I} \mid \theta_{I} \leq x\right\}$ for any $x \in[\underline{\theta}, \bar{\theta}]$. The function $\Psi^{b}$ in (3.7) has the following property for all $\underline{\theta} \leq x<\bar{\theta}$ :

$$
\begin{aligned}
\Psi^{b}\left(x, E_{F}\left\{\theta_{I} \mid \theta_{I}\right.\right. & \leq x\})-\Psi^{b}\left(x, E_{G}\left\{\theta_{I} \mid \theta_{I} \leq x\right\}\right) \\
& =m_{I}^{B}\left(x ; E_{F}\left\{\theta_{I} \mid \theta_{I} \leq x\right\}\right)^{2}-m_{I}^{B}\left(x ; E_{G}\left\{\theta_{I} \mid \theta_{I} \leq x\right\}\right)^{2} \geq 0 \text { (A.3) }
\end{aligned}
$$

Define $\theta_{F}^{b}$ such that: $\Psi^{b}\left(\theta_{F}^{b}, E_{F}\left\{\theta_{I} \mid \theta_{I} \leq \theta_{F}^{b}\right\}\right)=0$, where $\underline{\theta}<\theta_{F}^{b}<\bar{\theta}$ for any $\gamma<1$ (see proposition 1). Inequality (A.3), together with $\gamma<1$ and $\theta_{F}^{b}<\bar{\theta}$, gives:

$$
\Psi^{b}\left(\underline{\theta}, E_{G}\left\{\theta_{I} \mid \theta_{I} \leq \underline{\theta}\right\}\right)>0=\Psi^{b}\left(\theta_{F}^{b}, E_{F}\left\{\theta_{I} \mid \theta_{I} \leq \theta_{F}^{b}\right\}\right) \geq \Psi^{b}\left(\theta_{F}^{b}, E_{G}\left\{\theta_{I} \mid \theta_{I} \leq \theta_{F}^{b}\right\}\right)
$$

The intermediate value theorem implies that a $\theta_{G}^{b}$ exists, with $\underline{\theta}<\theta_{G}^{b} \leq \theta_{F}^{b}$, such that $\Psi^{b}\left(\theta_{G}^{b}, E_{G}\left\{\theta_{I} \mid \theta_{I} \leq \theta_{G}^{b}\right\}\right)=0$.

\section{Proof of Proposition 4}

If $\gamma=0$, then firm $I$ is indifferent between sharing technology $\theta_{I}$ and keeping it secret if $\widetilde{\Psi}^{b}\left(\theta_{I} ; \beta, N\right)=0$, where $\widetilde{\Psi}^{b}$ in (A.1) reduces to:

$$
\begin{aligned}
\widetilde{\Psi}^{b}(x ; \beta, N) & =m_{I}^{B}\left(x ; E\left\{\theta_{I} \mid \theta_{I} \leq x\right\}\right)^{2}-m_{I}^{b}(x, N x)^{2} \\
& =\left[m_{I}^{B}\left(x ; E\left\{\theta_{I} \mid \theta_{I} \leq x\right\}\right)+m_{I}^{b}(x, N x)\right]\left[m_{I}^{B}\left(x ; E\left\{\theta_{I} \mid \theta_{I} \leq x\right\}\right)-m_{I}^{b}(x, N x)\right] \\
& =\frac{\beta N\left[m_{I}^{B}\left(x ; E\left\{\theta_{I} \mid \theta_{I} \leq x\right\}\right)+m_{I}^{b}(x, N x)\right]}{2[2+(N-2) \beta][2+(2 N-1) \beta]} \psi^{b}(x ; \beta, N)
\end{aligned}
$$


with

$$
\psi^{b}(x ; \beta, N) \equiv 2[1+(N-1) \beta](\bar{\theta}-x)+\beta\left(E\left\{\theta_{I} \mid \theta_{I} \leq x\right\}-x\right)
$$

For $N=N^{\prime}$ the critical value $\theta^{b}\left(N^{\prime}\right)$ of equilibrium strategy (3.8) is such that $\psi^{b}\left(\theta^{b}\left(N^{\prime}\right) ; \beta, N^{\prime}\right)=0$. For $N=N^{\prime \prime}$, with $N^{\prime \prime}>N^{\prime}$, the function $\psi^{b}\left(x ; \beta, N^{\prime \prime}\right)$ can be rewritten as:

$$
\begin{aligned}
\psi^{b}\left(x ; \beta, N^{\prime \prime}\right) & =2\left[1+\left(N^{\prime \prime}-1\right) \beta\right](\bar{\theta}-x)+\beta\left(E\left\{\theta_{I} \mid \theta_{I} \leq x\right\}-x\right) \\
& =\psi^{b}\left(x ; \beta, N^{\prime}\right)+\left(N^{\prime \prime}-N^{\prime}\right) 2 \beta(\bar{\theta}-x)
\end{aligned}
$$

The evaluation of this expression for $x \in\left\{\theta^{b}\left(N^{\prime}\right), \bar{\theta}\right\}$ gives: $\psi^{b}\left(\theta^{b}\left(N^{\prime}\right) ; \beta, N^{\prime \prime}\right)=0+$ $\left(N^{\prime \prime}-N^{\prime}\right) 2 \beta\left(\bar{\theta}-\theta^{b}\left(N^{\prime}\right)\right)>0$, and $\psi^{b}\left(\bar{\theta} ; \beta, N^{\prime \prime}\right)=-\beta\left(\bar{\theta}-E\left\{\theta_{I}\right\}\right)<0$. Hence, the intermediate value theorem yields the existence of critical value $\theta^{b}\left(N^{\prime \prime}\right)$, with $\theta^{b}\left(N^{\prime}\right)<\theta^{b}\left(N^{\prime \prime}\right)<\bar{\theta}$, such that $\psi^{b}\left(\theta^{b}\left(N^{\prime \prime}\right) ; \beta, N^{\prime \prime}\right)=0$.

\section{Proof of Proposition 5}

This proof is analogous to the proof of proposition 4. If $\gamma=0$, then for $\beta=\beta^{\prime}$ the critical value $\theta^{b}\left(\beta^{\prime}\right)$ of equilibrium strategy (3.8) is such that $\psi^{b}\left(\theta^{b}\left(\beta^{\prime}\right) ; \beta^{\prime}, N\right)=0$, with $\psi^{b}$ as in (A.4). For $\beta=\beta^{\prime \prime}$, with $\beta^{\prime \prime}>\beta^{\prime}$, the function $\psi^{b}\left(x ; \beta^{\prime \prime}, N\right)$ can be rewritten as:

$$
\begin{aligned}
\psi^{b}\left(x ; \beta^{\prime \prime}, N\right) & =2\left[1+(N-1) \beta^{\prime \prime}\right](\bar{\theta}-x)+\beta^{\prime \prime}\left(E\left\{\theta_{I} \mid \theta_{I} \leq x\right\}-x\right) \\
& =\psi^{b}\left(x ; \beta^{\prime}, N\right)+\left(\beta^{\prime \prime}-\beta^{\prime}\right)\left[2(N-1)(\bar{\theta}-x)+E\left\{\theta_{I} \mid \theta_{I} \leq x\right\}-x\right] \\
& =\psi^{b}\left(x ; \beta^{\prime}, N\right)+\frac{\beta^{\prime \prime}-\beta^{\prime}}{\beta^{\prime}}\left[2(N-1) \beta^{\prime}(\bar{\theta}-x)+\beta^{\prime}\left(E\left\{\theta_{I} \mid \theta_{I} \leq x\right\}-x\right)\right] \\
& =\frac{\beta^{\prime \prime}}{\beta^{\prime}} \psi^{b}\left(x ; \beta^{\prime}, N\right)-\left(\frac{\beta^{\prime \prime}}{\beta^{\prime}}-1\right) 2(\bar{\theta}-x)
\end{aligned}
$$

The evaluation of this expression for particular values of $x$ gives: $\psi^{b}\left(\theta^{b}\left(\beta^{\prime}\right) ; \beta^{\prime \prime}, N\right)=$ $0-\left(\frac{\beta^{\prime \prime}}{\beta^{\prime}}-1\right) 2\left(\bar{\theta}-\theta^{b}\left(\beta^{\prime}\right)\right)<0$, and $\psi^{b}\left(\underline{\theta} ; \beta^{\prime \prime}, N\right)=2\left[1+(N-1) \beta^{\prime \prime}\right](\bar{\theta}-\underline{\theta})>0$. Hence, the intermediate value theorem yields the existence of critical value $\theta^{b}\left(\beta^{\prime \prime}\right)$, with $\underline{\theta}<\theta^{b}\left(\beta^{\prime \prime}\right)<\theta^{b}\left(\beta^{\prime}\right)$, such that $\psi^{b}\left(\theta^{b}\left(\beta^{\prime \prime}\right) ; \beta^{\prime \prime}, N\right)=0$.

\section{Proof of Proposition 6}

Under Cournot competition firm $I$ patents technology $\theta_{I}$, if

$$
\gamma \pi_{I}^{c}\left(\theta_{I}, N \bar{\theta}\right)+(1-\gamma) \pi_{I}^{c}\left(\theta_{I}, N \theta_{I}\right) \geq \pi_{I}^{C}\left(\theta_{I} ; E\left\{\theta_{I} \mid \varnothing\right\}\right)
$$




$$
\Leftrightarrow(1-\gamma)\left[q_{I}^{c}(x, N \bar{\theta})^{2}-q_{I}^{c}(x, N x)^{2}\right]+\left[q_{I}^{C}(x ; y)^{2}-q_{I}^{c}(x, N \bar{\theta})^{2}\right] \leq 0
$$

Using (4.5) and (4.6), this inequality is equivalent to $\Psi^{c}\left(\theta_{I}, E\left\{\theta_{I} \mid \varnothing\right\}\right) \leq 0$, where:

$$
\begin{aligned}
\Psi^{c}(x, y) \equiv & (1-\gamma)(\bar{\theta}-x)\left(2 q_{I}^{c}(x, N \bar{\theta})-\frac{\beta N(\bar{\theta}-x)}{(2+\beta N)(2-\beta)}\right) \\
& +\frac{\beta}{2}(x-y)\left(2 q_{I}^{c}(x, N \bar{\theta})+\frac{\beta}{2} \cdot \frac{\beta N(x-y)}{(2+\beta N)(2-\beta)}\right)
\end{aligned}
$$

for $x, y \in[\underline{\theta}, \bar{\theta}]$. The function $\Psi^{c}$ is decreasing and convex in $y$ (i.e., $\partial \Psi^{c} / \partial y<0$ and $\partial^{2} \Psi^{c} / \partial y^{2}>0$ for any $\left.x, y\right)$. The first partial derivative of $\Psi^{c}$ with respect to $x$ equals:

$$
\frac{\partial \Psi^{c}(x, y)}{\partial x}=-2(1-\gamma)\left(q_{I}^{c}(x, N \bar{\theta})+\frac{1}{2+\beta N}(\bar{\theta}-x)\right)+\beta\left(q_{I}^{c}(x, N \bar{\theta})-\frac{1}{2}(x-y)\right)
$$

since $\partial q_{I}^{c}(x, N \bar{\theta}) / \partial x=-[2+\beta(N-1)] /[(2+N \beta)(2-\beta)]$. The second partial derivative of $\Psi^{c}$ with respect to $x$ equals:

$\frac{\partial^{2} \Psi^{c}(x, y)}{\partial x^{2}}=\frac{1}{(2+N \beta)(2-\beta)}\left(2(1-\gamma)[4+\beta(N-2)]-\frac{\beta}{2}\left[8+4 \beta(N-1)-\beta^{2} N\right]\right)$

Notice that $\Psi^{c}$ is strictly convex (concave) in $x$ if and only if $\gamma<\widetilde{\gamma}(\operatorname{resp} . \gamma>\widetilde{\gamma}$ ) where:

$$
\widetilde{\gamma} \equiv 1-\frac{1}{2} \beta-\frac{\beta^{2} N(2-\beta)}{4[4+\beta(N-2)]}
$$

The evaluation of $\Psi^{c}$ for extreme values of $x$ and $\gamma<1$ yields the following. Firm $I$ has no incentive to patent the least efficient technology, since $\Psi^{c}(\bar{\theta}, y)>0$ for all $y<\bar{\theta}$, and $\Psi^{c}(\bar{\theta}, \bar{\theta})=0$. These properties of $\Psi^{c}$ imply that only the following four kinds of patenting rules can be chosen in equilibrium.

(a) Full disclosure: Firm $I$ patents any technology in equilibrium if and only if $\Psi^{c}(x, \bar{\theta}) \leq 0$ for all $x \in[\underline{\theta}, \bar{\theta}]$. Clearly, $\Psi^{c}(\bar{\theta}, \bar{\theta})=0$. Consequently, a necessary condition for the existence of a full disclosure equilibrium is $\partial \Psi^{c}(\bar{\theta}, \bar{\theta}) / \partial x \leq 0$. From substitution of $(x, y)=(\bar{\theta}, \bar{\theta})$ in (A.6) it follows immediately that the necessary condition is equivalent to: $\gamma \geq 1-\frac{1}{2} \beta$. Under this condition $\Psi^{c}(x, \bar{\theta})$ is strictly concave in $x$ (i.e., $\partial^{2} \Psi^{c} / \partial x^{2}>0$ ), since $1-\frac{1}{2} \beta>\widetilde{\gamma}$, as follows from (A.8). This implies that the necessary condition is also sufficient.

(b) Full secrecy: Firm $I$ keeps any technology secret in equilibrium if and only if $\Psi^{c}\left(x, E\left\{\theta_{I}\right\}\right) \geq 0$ for all $x \in[\underline{\theta}, \bar{\theta}]$. Clearly, $\Psi^{c}\left(\bar{\theta}, E\left\{\theta_{I}\right\}\right)>0$. First, if $\gamma<\widetilde{\gamma}$, then:

$$
\frac{\partial \Psi^{c}\left(x, E\left\{\theta_{I}\right\}\right)}{\partial x}<\frac{\partial \Psi^{c}\left(\bar{\theta}, E\left\{\theta_{I}\right\}\right)}{\partial x}<\lim _{\gamma \rightarrow 1-\beta / 2} \frac{\partial \Psi^{c}\left(\bar{\theta}, E\left\{\theta_{I}\right\}\right)}{\partial x}<0
$$


where the first inequality follows from convexity of $\Psi^{c}$ in $x$, the second inequality follows from the facts that $\partial \Psi^{c} / \partial x$ is increasing in $\gamma$ and $\widetilde{\gamma}<1-\frac{1}{2} \beta$, and the last inequality follows immediately from evaluating (A.6) for $(x, y)=\left(\bar{\theta}, E\left\{\theta_{I}\right\}\right)$ and $\gamma=1-\frac{1}{2} \beta$. Consequently, $\Psi^{c}\left(x, E\left\{\theta_{I}\right\}\right)>0$ for all $x$ if $\gamma<\widetilde{\gamma}$. Second, if $\gamma \geq \widetilde{\gamma}$, then the concavity of $\Psi^{c}$ in $x$ implies that the necessary and sufficient condition for full secrecy in equilibrium is $\Psi^{c}\left(\underline{\theta}, E\left\{\theta_{I}\right\}\right) \geq 0$. This inequality reduces to the following:

$$
\begin{aligned}
& (1-\gamma)(\bar{\theta}-\underline{\theta})\left(2 q_{I}^{c}(\underline{\theta}, N \bar{\theta})-\frac{\beta N(\bar{\theta}-\underline{\theta})}{(2+\beta N)(2-\beta)}\right) \\
\geq & \frac{\beta}{2}\left(E\left\{\theta_{I}\right\}-\underline{\theta}\right)\left(2 q_{I}^{c}(\underline{\theta}, N \bar{\theta})+\frac{\beta}{2} \cdot \frac{\beta N\left(\underline{\theta}-E\left\{\theta_{I}\right\}\right)}{(2+\beta N)(2-\beta)}\right)
\end{aligned}
$$

which is equivalent to $\gamma \leq \gamma^{o}$, with $\gamma^{o}$ as in (4.7). Clearly, $\gamma^{o}$ is decreasing in the average cost $E\left\{\theta_{I}\right\}$, and $\underline{\theta}<E\left\{\theta_{I}\right\}<\bar{\theta}$, which yields:

$$
\left(1-\frac{1}{2} \beta\right)-\frac{\beta^{2} N(2-\beta)(\bar{\theta}-\underline{\theta})}{4[2(2-\beta)(\alpha-\bar{\theta})+[4+\beta(N-2)](\bar{\theta}-\underline{\theta})]}<\gamma^{o}<1
$$

Furthermore, the comparison of (A.8) and (A.9) yields $\widetilde{\gamma}<\gamma^{o}$.

(c) Patent only the best technologies: This proof is similar to the proof of proposition 1. Suppose there exists a technology $\theta^{c}$, with $\underline{\theta}<\theta^{c}<\bar{\theta}$, such that firm $I$ chooses the patenting rule (4.8) in equilibrium. The beliefs consistent with this rule gives the expected cost $E\left\{\theta_{I} \mid \theta_{I}>\theta^{c}\right\}$. The rule (4.8) is an equilibrium rule if and only iff $\Psi^{c}\left(x, E\left\{\theta_{I} \mid \theta_{I}>\theta^{c}\right\}\right) \leq 0$ for all $x \leq \theta^{c}$, and $\Psi^{c}\left(x, E\left\{\theta_{I} \mid \theta_{I}>\theta^{c}\right\}\right) \geq 0$ otherwise. Define the continuous function $\widetilde{\Psi}^{c}(x) \equiv \Psi^{c}\left(x, E\left\{\theta_{I} \mid \theta_{I}>x\right\}\right)$ for $x \in[\underline{\theta}, \bar{\theta}]$. Evaluation of $\widetilde{\Psi}^{c}$ for extreme values of $x$ yields the following. On the one hand, $\widetilde{\Psi}^{c}(\underline{\theta})=\Psi^{c}\left(\underline{\theta}, E\left\{\theta_{I}\right\}\right)$, which is non-positive if and only if $\gamma \geq \gamma^{o}$ (see part b). On the other hand, $\widetilde{\Psi}^{c}(\bar{\theta})=\Psi^{c}(\bar{\theta}, \bar{\theta})=0$, and

$$
\begin{aligned}
\lim _{\theta \uparrow \bar{\theta}} \frac{d \widetilde{\Psi}^{c}(\theta)}{d x} & =\frac{\partial \Psi^{c}(\bar{\theta}, \bar{\theta})}{\partial x}+\lim _{\theta \uparrow \bar{\theta}} \frac{\left.\partial E\left\{\theta_{I} \mid \theta_{I}>\theta\right\}\right)}{\partial \theta} \cdot \frac{\partial \Psi^{c}(\bar{\theta}, \bar{\theta})}{\partial y} \\
& =\left[\frac{1}{2} \beta-2(1-\gamma)\right] q_{I}^{c}(\bar{\theta}, N \bar{\theta})
\end{aligned}
$$

since

$$
\frac{\partial \Psi^{c}(\bar{\theta}, \bar{\theta})}{\partial x}=[\beta-2(1-\gamma)] q_{I}^{c}(\bar{\theta}, N \bar{\theta}), \frac{\partial \Psi^{c}(\bar{\theta}, \bar{\theta})}{\partial y}=-\beta q_{I}^{c}(\bar{\theta}, N \bar{\theta})
$$


and

$$
\begin{aligned}
\lim _{\theta \uparrow \bar{\theta}} \frac{\partial E\left\{\theta_{I} \mid \theta_{I}>\theta\right\}}{\partial \theta} & =\lim _{\theta \uparrow \bar{\theta}} \frac{\partial}{\partial \theta}\left(\int_{\theta}^{\bar{\theta}} \frac{f(z)}{1-F(\theta)} z d z\right) \\
& =\lim _{\theta \uparrow \bar{\theta}} \frac{f(\theta)}{1-F(\theta)}\left(E\left\{\theta_{I} \mid \theta_{I}>\theta\right\}-\theta\right) \\
& =f(\bar{\theta}) \lim _{\theta \uparrow \bar{\theta}} \frac{\left.E\left\{\theta_{I} \mid \theta_{I}>\theta\right\}\right)-\theta}{1-F(\theta)}=\frac{1}{2}
\end{aligned}
$$

where the last equality follows from the application of the De L'Hospital rule, i.e.,

$$
\begin{aligned}
\lim _{\theta \uparrow \bar{\theta}} \frac{\left.E\left\{\theta_{I} \mid \theta_{I}>\theta\right\}\right)-\theta}{1-F(\theta)} & =\lim _{\theta \uparrow \bar{\theta}} \frac{\frac{f(\theta)}{1-F(\theta)}\left(E\left\{\theta_{I} \mid \theta_{I}>\theta\right\}-\theta\right)-1}{-f(\theta)} \\
& =\frac{1}{f(\bar{\theta})}-\lim _{\theta \uparrow \bar{\theta}} \frac{E\left\{\theta_{I} \mid \theta_{I}>\theta\right\}-\theta}{1-F(\theta)}
\end{aligned}
$$

yielding

$$
\lim _{\theta \uparrow \bar{\theta}} \frac{\left.E\left\{\theta_{I} \mid \theta_{I}>\theta\right\}\right)-\theta}{1-F(\theta)}=\frac{1}{2 f(\bar{\theta})}
$$

Hence, (A.10) yields: $d \widetilde{\Psi}^{c}(\bar{\theta}) / d x<0$ iff $\gamma<1-\frac{1}{4} \beta$. If $d \widetilde{\Psi}^{c}(\bar{\theta}) / d x<0$, then there exists a $\theta^{\prime}$, with $\theta^{\prime}<\bar{\theta}$, such that $\widetilde{\Psi}^{c}\left(\theta^{\prime}\right)>0$. Consequently, if $\gamma^{o}<1-\frac{1}{4} \beta$, then for any $\gamma^{o}<\gamma<1-\frac{1}{4} \beta$ the intermediate value theorem implies that there exists an $\theta^{c}$ with $\underline{\theta}<\theta^{c}<\bar{\theta}$ such that $\widetilde{\Psi}^{c}\left(\theta^{c}\right)=0$. In other words, the equilibrium rule (4.8) with $\underline{\theta}<\theta^{c}<\bar{\theta}$ exists if $\gamma^{o}<\gamma<1-\frac{1}{4} \beta$.

(d) Patent only intermediate technologies: Finally, if $\gamma<\widetilde{\gamma}$, an equilibrium may exist in which firm $I$ patents any technology $\theta_{I}$ in some interval $[l, h]$, with $\underline{\theta}<l<h<\bar{\theta}$, but keeps other technologies secret. The posterior belief consistent with such a patenting rule gives the expected cost $\mu_{l h} \equiv E\left\{\theta_{I} \mid \theta_{I} \notin[l, h]\right\}$. Two necessary equilibrium conditions are:

$$
\Psi^{c}\left(z, E\left\{\theta_{I} \mid \theta_{I} \notin[l, h]\right\}\right)=0 \text { for } z \in\{l, h\}
$$

Using (A.5), this system of equations can be rewritten as $\gamma=\gamma^{I}\left(z ; \mu_{l h}\right)$ for $z \in\{l, h\}$, with:

$$
\gamma^{I}\left(z ; \mu_{l h}\right) \equiv 1+\frac{\beta}{2}\left(\frac{q_{I}^{c}(z, N \bar{\theta})+q_{I}^{C}\left(z ; \mu_{l h}\right)}{\bar{\theta}-z}\right)\left(\frac{z-\mu_{l h}}{q_{I}^{c}(z, N \bar{\theta})+q_{I}^{c}(z, N z)}\right)
$$

In other words, an equilibrium with patenting of intermediate technologies exists if there exists a pair $l$ and $h$ with $\underline{\theta}<l<h<\bar{\theta}$ such that $\gamma^{I}\left(l ; \mu_{l h}\right)=\gamma^{I}\left(h ; \mu_{l h}\right)$, which 
(by 4.5 and 4.6 ) is equivalent to:

$$
\begin{aligned}
( & \left.\frac{q_{I}^{c}(l, N \bar{\theta})+q_{I}^{C}\left(l ; \mu_{l h}\right)}{\bar{\theta}-l}\right)\left(\frac{l-\mu_{l h}}{q_{I}^{c}(l, N \bar{\theta})+q_{I}^{c}(l, N l)}\right) \\
= & \left(\frac{q_{I}^{c}(l, N \bar{\theta})+q_{I}^{C}\left(l ; \mu_{l h}\right)}{\bar{\theta}-l}+\frac{(h-l)\left[q_{I}^{c}(\bar{\theta}, N \bar{\theta})+q_{I}^{C}\left(\bar{\theta} ; \mu_{l h}\right)\right]}{(\bar{\theta}-l)(\bar{\theta}-h)}\right) \\
& \cdot\left(\frac{l-\mu_{l h}}{q_{I}^{c}(l, N \bar{\theta})+q_{I}^{c}(l, N l)}+\frac{(h-l)\left[q_{I}^{c}\left(\mu_{l h}, N \bar{\theta}\right)+q_{I}^{c}\left(\mu_{l h}, N \mu_{l h}\right)\right]}{\left[q_{I}^{c}(l, N \bar{\theta})+q_{I}^{c}(l, N l)\right]\left[q_{I}^{c}(h, N \bar{\theta})+q_{I}^{c}(h, N h)\right]}\right)
\end{aligned}
$$

This, in turn (again, using 4.5 and 4.6), is equivalent (for $\underline{\theta}<l<h<\bar{\theta}$ ) to

$$
\begin{aligned}
0= & {\left[q_{I}^{c}(l, N \bar{\theta})+q_{I}^{C}\left(l ; \mu_{l h}\right)\right]\left[q_{I}^{c}\left(\mu_{l h}, N \bar{\theta}\right)+q_{I}^{c}\left(\mu_{l h}, N \mu_{l h}\right)\right](\bar{\theta}-h) } \\
& +\left[q_{I}^{c}(l, N \bar{\theta})+q_{I}^{c}(l, N l)\right]\left[q_{I}^{c}(\bar{\theta}, N \bar{\theta})+q_{I}^{C}\left(\bar{\theta} ; \mu_{l h}\right)\right]\left(h-\mu_{l h}\right)
\end{aligned}
$$

which can be rewritten as follows

$$
\begin{aligned}
0= & {\left[q_{I}^{c}\left(\mu_{l h}, N \bar{\theta}\right)+q_{I}^{c}\left(\mu_{l h}, N \mu_{l h}\right)\right](\bar{\theta}-h)+\left[q_{I}^{c}(\bar{\theta}, N \bar{\theta})+q_{I}^{C}\left(\bar{\theta} ; \mu_{l h}\right)\right]\left(h-\mu_{l h}\right) } \\
& +\frac{q_{I}^{C}\left(l ; \mu_{l h}\right)-q_{I}^{c}(l, N l)}{q_{I}^{c}(l, N \bar{\theta})+q_{I}^{c}(l, N l)}\left[q_{I}^{c}\left(\mu_{l h}, N \bar{\theta}\right)+q_{I}^{c}\left(\mu_{l h}, N \mu_{l h}\right)\right](\bar{\theta}-h)
\end{aligned}
$$

This equality cannot hold for $\underline{\theta}<l<h<\bar{\theta}$, since:

$$
\begin{aligned}
& {\left[q_{I}^{c}\left(\mu_{l h}, N \bar{\theta}\right)+q_{I}^{c}\left(\mu_{l h}, N \mu_{l h}\right)\right](\bar{\theta}-h)+\left[q_{I}^{c}(\bar{\theta}, N \bar{\theta})+q_{I}^{C}\left(\bar{\theta} ; \mu_{l h}\right)\right]\left(h-\mu_{l h}\right) } \\
= & {\left[q_{I}^{c}(\bar{\theta}, N \bar{\theta})+q_{I}^{C}\left(\bar{\theta} ; \mu_{l h}\right)\right]\left(\bar{\theta}-\mu_{l h}\right) } \\
& +\left[q_{I}^{c}\left(\mu_{l h}, N \bar{\theta}\right)+q_{I}^{c}\left(\mu_{l h}, N \mu_{l h}\right)-q_{I}^{c}(\bar{\theta}, N \bar{\theta})-q_{I}^{C}\left(\bar{\theta} ; \mu_{l h}\right)\right](\bar{\theta}-h) \\
= & {\left[q_{I}^{c}(\bar{\theta}, N \bar{\theta})+q_{I}^{C}\left(\bar{\theta} ; \mu_{l h}\right)\right]\left(\bar{\theta}-\mu_{l h}\right)+\frac{\left[2(2-\beta)+\beta N\left(1-\frac{\beta}{2}\right)\right]\left(\bar{\theta}-\mu_{l h}\right)}{(2+\beta N)(2-\beta)}(\bar{\theta}-h)>0 }
\end{aligned}
$$

and

$$
\begin{aligned}
q_{I}^{C}\left(l ; \mu_{l h}\right)-q_{I}^{c}(l, N l) & =q_{I}^{c}(l, N \bar{\theta})-q_{I}^{c}(l, N l)+\frac{\beta}{2} \cdot \frac{\beta N}{(2+\beta N)(2-\beta)}\left(l-\mu_{l h}\right) \\
& =\frac{\beta N}{(2+\beta N)(2-\beta)}\left[\bar{\theta}-\left(\left(1-\frac{\beta}{2}\right) l+\frac{\beta}{2} \mu_{l h}\right)\right]>0
\end{aligned}
$$

since $\mu_{l h}<\bar{\theta}$, and all other terms are strictly positive as well. In other words, an equilibrium in which firm $I$ patents only intermediate technologies cannot exist. 


\section{B Extensions}

Here I present a brief description of some model extensions. First, I adopt a different demand function. Second, I reverse the timing. Third, I analyze a model with two innovative firms. Finally, I give some implications for the expected consumer surplus.

\section{B.1 Demand}

Assume that the direct demand for firm $\ell$ 's good is (5.2) for $\ell \in\{I, 1, . . N\}$. Profitmaximization by firm $\ell$ gives firm $\ell$ 's best response (for $\ell, k \in\{I, 1, . ., N\}$ ):

$$
r_{\ell}\left(\mathbf{p}_{-\ell} ; \theta_{\ell}\right)=\frac{1}{2} \theta_{\ell}+\frac{N+1}{2(N+1+N b)}\left(a+\frac{b}{N+1} \sum_{k \neq \ell} p_{k}\right)
$$

Solving for the equilibrium prices in the cases of complete and incomplete information gives the following price-cost margins for firm $I$, respectively:

$$
\begin{aligned}
m_{I}^{s}\left(\theta_{I}, \sum_{j=1}^{N} \theta_{k}\right) & =\frac{1}{2(N+1)+N b}\left((N+1)\left(a-\theta_{I}\right)+\frac{(N+1+N b) b \sum_{j=1}^{N}\left(\theta_{j}-\theta_{I}\right)}{2(N+1)+(2 N+1) b}\right) \\
m_{I}^{S}\left(\theta_{I} ; E\left\{\theta_{I} \mid \varnothing\right\}\right) & =m_{I}^{s}\left(\theta_{I}, N \bar{\theta}\right)+\frac{b}{2} \frac{b N\left(E\left\{\theta_{I} \mid \varnothing\right\}-\theta_{I}\right)}{[2(N+1)+N b][2(N+1)+(2 N+1) b]}
\end{aligned}
$$

Firm I's product market profit equals (for $r \in\{s, S\}$ ):

$$
\pi_{I}^{r}(\bullet)=\frac{N+1+N b}{(N+1)^{2}} m_{I}^{r}(\bullet)^{2}
$$

The profit gain from secrecy instead of patenting reduces to $\frac{N+1+N b}{(N+1)^{2}} \Psi^{s}\left(\theta_{I}, E\left\{\theta_{I} \mid \varnothing\right\}\right)$, where $\Psi^{s}(x, y)$ is as in (3.7) with $m_{I}^{b}$ and $m_{I}^{B}$ replaced by $m_{I}^{s}$ and $m_{I}^{S}$ respectively. Using these expressions, it is easy to show the same results as in Propositions $1-5 .{ }^{17}$

\section{B.2 Timing}

First, the function $\Psi^{T}(x, y)$ in $(5.3)$ is convex in $x$, since

$$
\begin{aligned}
\frac{\partial^{2} \Psi^{T}}{\partial x^{2}} & =\frac{d\left[m_{I}^{B}(x ; y)-m_{I}^{b}(x, N[\gamma \bar{\theta}+(1-\gamma) x])\right]}{d x}\left[\frac{\partial m_{I}^{B}(x ; y)}{\partial x}+\frac{\partial m_{I}^{b}(x, N[\gamma \bar{\theta}+(1-\gamma) x])}{\partial x}\right] \\
& >0
\end{aligned}
$$

\footnotetext{
${ }^{17}$ In particular, the comparative statics analyses with respect to $N$ and $b$ reduce to analyzing the properties of the function $\psi^{s}(x ; b, N)=2(N+1+N b)(\bar{\theta}-x)+b\left(E\left\{\theta_{i} \mid \theta_{i} \leq x\right\}\right)$ as in (A.4).
} 
since all terms are negative. Also if $\gamma<1$, then $\Psi^{T}(\bar{\theta}, y)<0<\Psi^{T}(\underline{\theta}, y)$ holds for $y<\bar{\theta}$, and in particular $\Psi^{T}\left(\bar{\theta}, E\left\{\theta_{I}\right\}\right)<0<\Psi^{T}(\underline{\theta}, \underline{\theta})$. This confirms that Proposition 1 holds. Second, the function $\Psi^{T}(x, y)$ in (5.3) is decreasing in $\gamma$, since

$$
\frac{\partial \Psi^{T}}{\partial \gamma}=-2 m_{I}^{b}(x, N[\gamma \bar{\theta}+(1-\gamma) x]) \frac{\partial m_{I}^{b}(x, N[\gamma \bar{\theta}+(1-\gamma) x])}{\partial \gamma}<0
$$

This establishes that Proposition 2 also holds with the reverse timing. The remaining comparative statics results are identical to those in the original model.

\section{B.3 Two-Sided Asymmetric Information}

Suppose that patents are invalid, $\gamma=0$. First, I present the equilibrium pricing strategies. Second, I characterize the patenting strategies.

\section{B.3.1 Pricing Strategies}

Take any subset $\mathcal{S}_{k} \subseteq[\underline{\theta}, \bar{\theta}]$ and $\mathcal{P}_{k} \equiv[\underline{\theta}, \bar{\theta}] \backslash \mathcal{S}_{k}$, and assume that firm $\ell$ has beliefs consistent with the adoption of the following generic patenting strategy by firm $k$ (for $\ell, k \in\left\{I_{1}, I_{2}\right\}$ and $\left.\ell \neq k\right)$ :

$$
\widehat{s}_{k}\left(\theta_{k}\right)= \begin{cases}\varnothing, & \text { if } \theta_{k} \in \mathcal{S}_{k} \\ \theta_{k}, & \text { if } \theta_{k} \in \mathcal{P}_{k}\end{cases}
$$

That is, the expected cost of firm $k$ after adoption of secrecy is $E\left\{\theta_{k} \mid \theta_{k} \in \mathcal{S}_{k}\right\}$.

If both firms share their technologies, then they set equilibrium prices which yield the following price-cost margins (for $\ell, k \in\left\{I_{1}, I_{2}\right\}$ and $\ell \neq k$ ):

$$
m_{\ell}^{P P}\left(\theta_{\ell} ; \theta_{\ell}, \theta_{k}\right) \equiv p_{\ell}^{P P}\left(\theta_{\ell} ; \theta_{\ell}, \theta_{k}\right)-\min \left\{\theta_{\ell}, \theta_{k}\right\}=\frac{1-\beta}{2-\beta}\left(\alpha-\min \left\{\theta_{\ell}, \theta_{k}\right\}\right) .
$$

If both firms keep their technologies secret, firm $\ell$ chooses the following price-cost margin in equilibrium (for $\ell, k \in\left\{I_{1}, I_{2}\right\}$ and $\ell \neq k$ ):

$$
\begin{aligned}
m_{\ell}^{S S}\left(\theta_{\ell} ; \mathcal{S}_{\ell}, \mathcal{S}_{k}\right)= & p_{\ell}^{S S}\left(\theta_{\ell} ; \mathcal{S}_{\ell}, \mathcal{S}_{k}\right)-\theta_{\ell}=\frac{1-\beta}{2-\beta}\left(\alpha-\theta_{\ell}\right) \\
& +\frac{\beta}{4-\beta^{2}}\left(E\left\{\theta_{k} \mid \theta_{k} \in \mathcal{S}_{k}\right\}-\theta_{\ell}+\frac{\beta}{2}\left[E\left\{\theta_{\ell} \mid \theta_{\ell} \in \mathcal{S}_{\ell}\right\}-\theta_{\ell}\right]\right)
\end{aligned}
$$

If firm $\ell$ shares technology $\theta_{\ell}$ and firm $k$ conceals, the firms' first-order conditions are as follows (for $\ell, k \in\left\{I_{1}, I_{2}\right\}$ and $\ell \neq k$ ):

$$
\begin{array}{r}
2 p_{\ell}\left(\theta_{\ell}\right)=(1-\beta) \alpha+\theta_{\ell}+\beta \int_{\theta \in \mathcal{S}_{k}} f_{k}\left(\theta \mid \theta_{k} \in \mathcal{S}_{k}\right) p_{k}\left(\theta, \theta_{\ell}\right) d \theta \\
\text { and } 2 p_{k}\left(\theta_{k}, \theta_{\ell}\right)=(1-\beta) \alpha+\min \left\{\theta_{\ell}, \theta_{k}\right\}+\beta p_{\ell}\left(\theta_{\ell}\right) .
\end{array}
$$


In this case (firm $\ell$ shares, firm $k$ conceals) firm $\ell$ sets the following equilibrium margin:

$$
\begin{aligned}
m_{\ell}^{P S}\left(\theta_{\ell} ; \theta_{\ell}, \mathcal{S}_{k}\right) & =p_{\ell}^{P S}\left(\theta_{\ell} ; \theta_{\ell}, \mathcal{S}_{k}\right)-\theta_{\ell} \\
& =\frac{1-\beta}{2-\beta}\left(\alpha-\theta_{\ell}\right)+\frac{\beta}{4-\beta^{2}}\left(E\left(\min \left\{\theta_{\ell}, \theta_{k}\right\} \mid \theta_{k} \in \mathcal{S}_{k}\right)-\theta_{\ell}\right),
\end{aligned}
$$

with $E\left(\min \left\{\theta_{\ell}, \theta_{k}\right\} \mid \theta_{k} \in \mathcal{S}_{k}\right)=F_{k}\left(\theta_{k} \mid \theta_{k} \in \mathcal{S}_{k}\right) E\left\{\theta_{k} \mid \theta_{k} \leq \theta_{\ell}, \theta_{k} \in \mathcal{S}_{k}\right\}+\left[1-F_{k}\left(\theta_{k} \mid \theta_{k} \in \mathcal{S}_{k}\right)\right] \theta_{\ell}$. Similarly, if firm $\ell$ hides $\theta_{\ell}$ and firm $k$ shares, firm $\ell$ sets the following price-cost margin in equilibrium (for $\ell, k \in\left\{I_{1}, I_{2}\right\}$ and $\ell \neq k$ ):

$$
\begin{aligned}
m_{\ell}^{S P}\left(\theta_{\ell} ; \mathcal{S}_{\ell}, \theta_{k}\right)= & p_{\ell}^{S P}\left(\theta_{\ell} ; \mathcal{S}_{\ell}, \theta_{k}\right)-\min \left\{\theta_{\ell}, \theta_{k}\right\} \\
= & \frac{1-\beta}{2-\beta}\left(\alpha-\min \left\{\theta_{\ell}, \theta_{k}\right\}\right)+\frac{\beta}{4-\beta^{2}}\left(\theta_{k}-\min \left\{\theta_{\ell}, \theta_{k}\right\}\right. \\
& \left.+\frac{\beta}{2}\left[E\left(\min \left\{\theta_{\ell}, \theta_{k}\right\} \mid \theta_{\ell} \in \mathcal{S}_{\ell}\right)-\min \left\{\theta_{\ell}, \theta_{k}\right\}\right]\right) .
\end{aligned}
$$

Firm $\ell$ 's expected equilibrium product market profit is (for any $t_{\ell}$ and $t_{k}$ ):

$$
\pi_{\ell}^{t_{\ell} t_{k}}\left(\theta_{\ell} ; \bullet\right)=\frac{1}{1-\beta^{2}} m_{\ell}^{t_{\ell} t_{k}}\left(\theta_{\ell} ; \bullet\right)^{2}
$$

\section{B.3.2 Patenting Strategies}

The analysis of the equilibrium patenting strategies in the model with two-sided asymmetric information is analogous to the analysis in the model with one-sided asymmetric information (see the proof of proposition 1). Suppose that firm $k$ chooses the technology sharing rule $\widehat{s}_{k}$ in (B.1). Further, suppose that firm $k$ has beliefs consistent with (B.1), with $k=\ell$, for some subsets $\mathcal{S}_{\ell} \subseteq[\underline{\theta}, \bar{\theta}]$ and $\mathcal{P}_{\ell}=[\underline{\theta}, \bar{\theta}] \backslash \mathcal{S}_{\ell}$. Given these assumptions, the difference of the expected profit from technology sharing and secrecy for firm $\ell$ is:

$$
\begin{aligned}
\Psi^{B}\left(\theta_{\ell} ; \mathcal{S}_{\ell}, \mathcal{S}_{k}\right) \equiv & \int_{\theta_{k} \in \mathcal{P}_{k}}\left[\pi_{\ell}^{P P}\left(\theta_{\ell} ; \theta_{\ell}, \theta_{k}\right)-\pi_{\ell}^{S P}\left(\theta_{\ell} ; \mathcal{S}_{\ell}, \theta_{k}\right)\right] f_{k}\left(\theta_{k}\right) d \theta_{k} \\
& +\int_{\theta_{k} \in \mathcal{S}_{k}}\left[\pi_{\ell}^{P S}\left(\theta_{\ell} ; \theta_{\ell}, \mathcal{S}_{k}\right)-\pi_{\ell}^{S S}\left(\theta_{\ell} ; \mathcal{S}_{\ell}, \mathcal{S}_{k}\right)\right] f_{k}\left(\theta_{k}\right) d \theta_{k}
\end{aligned}
$$

where

$$
\begin{aligned}
\pi_{\ell}^{P P}\left(\theta_{\ell} ; \theta_{\ell}, \theta_{k}\right)-\pi_{\ell}^{S P}\left(\theta_{\ell} ; \mathcal{S}_{\ell}, \theta_{k}\right)= & \frac{1}{1-\beta^{2}}\left(m_{\ell}^{P P}\left(\theta_{\ell} ; \theta_{\ell}, \theta_{k}\right)^{2}-m_{\ell}^{S P}\left(\theta_{\ell} ; \mathcal{S}_{\ell}, \theta_{k}\right)^{2}\right) \\
= & \frac{1}{1-\beta^{2}}\left[m_{\ell}^{P P}\left(\theta_{\ell} ; \theta_{\ell}, \theta_{k}\right)-m_{\ell}^{S P}\left(\theta_{\ell} ; \mathcal{S}_{\ell}, \theta_{k}\right)\right] \\
& \cdot\left[m_{\ell}^{P P}\left(\theta_{\ell} ; \theta_{\ell}, \theta_{k}\right)+m_{\ell}^{S P}\left(\theta_{\ell} ; \mathcal{S}_{\ell}, \theta_{k}\right)\right]
\end{aligned}
$$


and a similar expression for $\pi_{\ell}^{P S}\left(\theta_{\ell} ; \theta_{\ell}, \mathcal{S}_{k}\right)-\pi_{\ell}^{S S}\left(\theta_{\ell} ; \mathcal{S}_{\ell}, \mathcal{S}_{k}\right)$. The evaluation of $\Psi^{B}$ at extreme values of $\theta_{\ell}$ gives the following: $\Psi^{B}\left(\underline{\theta} ; \mathcal{S}_{\ell}, \mathcal{S}_{k}\right)<0 \leq \Psi^{B}\left(\bar{\theta} ; \mathcal{S}_{\ell}, \mathcal{S}_{k}\right)$ for any $\mathcal{S}_{\ell}$ and $\mathcal{S}_{k}$. The second derivative of $\Psi^{B}$ equals:

$$
\begin{aligned}
\frac{\partial^{2} \Psi^{B}\left(\theta_{\ell} ; \mathcal{S}_{\ell}, \mathcal{S}_{k}\right)}{\partial \theta_{\ell}^{2}}= & \frac{1}{1-\beta^{2}} \int_{\theta_{k} \in \mathcal{P}_{k}}\left(\frac{\partial m_{\ell}^{P P}\left(\theta_{\ell} ; \theta_{\ell}, \theta_{k}\right)}{\partial \theta_{\ell}}-\frac{\partial m_{\ell}^{S P}\left(\theta_{\ell} ; \mathcal{S}_{\ell}, \theta_{k}\right)}{\partial \theta_{\ell}}\right) \\
& \cdot\left(\frac{\partial m_{\ell}^{P P}\left(\theta_{\ell} ; \theta_{\ell}, \theta_{k}\right)}{\partial \theta_{\ell}}+\frac{\partial m_{\ell}^{S P}\left(\theta_{\ell} ; \mathcal{S}_{\ell}, \theta_{k}\right)}{\partial \theta_{\ell}}\right) f_{k}\left(\theta_{k}\right) d \theta_{k} \\
+\frac{1}{1-\beta^{2}} \operatorname{Pr}\left[\theta_{k} \in\right. & \left.\mathcal{S}_{k}\right]\left[\left(\frac{\partial m_{\ell}^{P S}\left(\theta_{\ell} ; \theta_{\ell}, \mathcal{S}_{k}\right)}{\partial \theta_{\ell}}-\frac{\partial m_{\ell}^{S S}\left(\theta_{\ell} ; \mathcal{S}_{\ell}, \mathcal{S}_{k}\right)}{\partial \theta_{\ell}}\right)\right. \\
& \cdot\left(\frac{\partial m_{\ell}^{P S}\left(\theta_{\ell} ; \theta_{\ell}, \mathcal{S}_{k}\right)}{\partial \theta_{\ell}}+\frac{\partial m_{\ell}^{S S}\left(\theta_{\ell} ; \mathcal{S}_{\ell}, \mathcal{S}_{k}\right)}{\partial \theta_{\ell}}\right) \\
& \left.+2 m_{\ell}^{P S}\left(\theta_{\ell} ; \theta_{\ell}, \mathcal{S}_{k}\right) \frac{\partial^{2} m_{\ell}^{P S}\left(\theta_{\ell} ; \theta_{\ell}, \mathcal{S}_{k}\right)}{\partial \theta_{\ell}^{2}}\right]
\end{aligned}
$$

since for any $\theta_{\ell} \in[\underline{\theta}, \bar{\theta}]$

$$
\frac{\partial^{2} m_{\ell}^{P P}\left(\theta_{\ell} ; \theta_{\ell}, \theta_{k}\right)}{\partial \theta_{\ell}^{2}}=\frac{\partial^{2} m_{\ell}^{S P}\left(\theta_{\ell} ; \mathcal{S}_{\ell}, \theta_{k}\right)}{\partial \theta_{\ell}^{2}}=\frac{\partial^{2} m_{\ell}^{S S}\left(\theta_{\ell} ; \mathcal{S}_{\ell}, \mathcal{S}_{k}\right)}{\partial \theta_{\ell}^{2}}=0
$$

First, using (B.2) and (B.5), it is immediate that $\frac{\partial m_{\ell}^{P P}\left(\theta_{\ell} ; \theta_{\ell}, \theta_{k}\right)}{\partial \theta_{\ell}}-\frac{\partial m_{\ell}^{S P}\left(\theta_{\ell} ; \mathcal{S}_{\ell}, \theta_{k}\right)}{\partial \theta_{\ell}} \geq 0$ and $\frac{\partial m_{\ell}^{P P}\left(\theta_{\ell} ; \theta_{\ell}, \theta_{k}\right)}{\partial \theta_{\ell}}+\frac{\partial m_{\ell}^{S P}\left(\theta_{\ell} ; \mathcal{S}_{\ell}, \theta_{k}\right)}{\partial \theta_{\ell}} \leq 0$ for any $\theta_{\ell}$ and $\theta_{k}$, since $\partial \min \left\{\theta_{\ell}, \theta_{k}\right\} / \partial \theta_{\ell} \geq 0$. Second, using (B.3) and (B.4), gives $\frac{\partial m_{\ell}^{P S}\left(\theta_{\ell} ; \theta_{\ell}, \mathcal{S}_{k}\right)}{\partial \theta_{\ell}}-\frac{\partial m_{\ell}^{S S}\left(\theta_{\ell} ; \mathcal{S}_{\ell}, \mathcal{S}_{k}\right)}{\partial \theta_{\ell}}>0$ and $\frac{\partial m_{\ell}^{P S}\left(\theta_{\ell} ; \theta_{\ell}, \mathcal{S}_{k}\right)}{\partial \theta_{\ell}}+$ $\frac{\partial m_{\ell}^{S S}\left(\theta_{\ell} ; \mathcal{S}_{\ell}, \mathcal{S}_{k}\right)}{\partial \theta_{\ell}}<0$, since $\partial E\left(\min \left\{\theta_{\ell}, \theta_{k}\right\} \mid \theta_{k} \in \mathcal{S}_{k}\right) / \partial \theta_{\ell}=\operatorname{Pr}\left[\theta_{k} \in \mathcal{S}_{k} \cap\left[\theta_{\ell}, \bar{\theta}\right]\right] / \operatorname{Pr}\left[\theta_{k} \in\right.$ $\left.\mathcal{S}_{k}\right] \in[0,1]$. Finally,

$$
\frac{\partial^{2} m_{\ell}^{P S}\left(\theta_{\ell} ; \theta_{\ell}, \mathcal{S}_{k}\right)}{\partial \theta_{\ell}^{2}}=\frac{\beta}{4-\beta^{2}} \cdot \frac{\partial^{2} E\left(\min \left\{\theta_{\ell}, \theta_{k}\right\} \mid \theta_{k} \in \mathcal{S}_{k}\right)}{\partial \theta_{\ell}^{2}} \leq 0 .
$$

Hence, $\partial^{2} \Psi^{B}\left(\theta_{\ell} ; \mathcal{S}_{\ell}, \mathcal{S}_{k}\right) / \partial \theta_{\ell}^{2} \leq 0$, i.e., $\Psi^{B}\left(\theta_{\ell} ; \mathcal{S}_{\ell}, \mathcal{S}_{k}\right)$ is (weakly) concave in $\theta_{\ell}$. This fact, in combination with $\Psi^{B}(\underline{\theta} ; \bullet)<0 \leq \Psi^{B}(\bar{\theta} ; \bullet)$, implies that firm $\ell$ 's equilibrium patenting strategy is (B.1) for $k=\ell$, with $\mathcal{S}_{\ell}=\left[\underline{\theta}, \theta_{\ell}^{b}\right]$ for some $\underline{\theta} \leq \theta_{\ell}^{b} \leq \bar{\theta}$. The evaluation of $\Psi^{B}\left(x ;[\underline{\theta}, x], \mathcal{S}_{k}\right)$ for extreme values of $x$ gives:

$$
\Psi^{B}\left(\underline{\theta} ;[\underline{\theta}, \underline{\theta}], \mathcal{S}_{k}\right)<0<\Psi^{B}\left(\bar{\theta} ;[\underline{\theta}, \bar{\theta}], \mathcal{S}_{k}\right)
$$

for any $\mathcal{S}_{k} \subseteq[\underline{\theta}, \bar{\theta}]$, Hence, the intermediate value theorem implies that (for any $\left.\mathcal{S}_{k} \subseteq[\underline{\theta}, \bar{\theta}]\right)$ there exists a $\theta_{\ell}^{b}$, with $\underline{\theta}<\theta_{\ell}^{b}<\bar{\theta}$, such that $\Psi^{B}\left(\theta_{\ell}^{b} ;\left[\underline{\theta}, \theta_{\ell}^{b}\right], \mathcal{S}_{k}\right)=0$. 


\section{B.4 Consumer Surplus}

Here I analyze the effects of product market competition and strategic patenting on the consumer surplus. The consumer surplus for any output bundle $\mathbf{q}$ equals (using definition 2.2):

$$
S(\mathbf{q}) \equiv U(\mathbf{q} ; \omega)-\left(\sum_{\ell} p_{\ell} q_{\ell}+\omega\right)=\frac{1}{2} \sum_{\ell}\left(q_{\ell}^{2}+\beta q_{\ell} \sum_{k \neq \ell} q_{k}\right)
$$

In equilibrium the consumer surplus $S^{r}(\bullet) \equiv S\left(q_{I}^{r}(\bullet), q_{n}^{r}(\bullet)\right)$ is reached under regime $r$ with $r \in\{b, B\}$. The expected consumer surplus, given equilibrium rule (3.8), equals:

$$
\begin{aligned}
C S^{b}(\gamma) \equiv & F\left(\theta^{b}\right) E\left\{S^{B}\left(\theta_{I} ; E\left\{\theta_{I} \mid \theta_{I} \leq \theta^{b}\right\}\right) \mid \theta_{I} \leq \theta^{b}\right\} \\
& +\left[1-F\left(\theta^{b}\right)\right] E\left\{\gamma S^{b}\left(\theta_{I}, \bar{\theta}\right)+(1-\gamma) S^{b}\left(\theta_{I}, \theta_{I}\right) \mid \theta_{I}>\theta^{b}\right\}
\end{aligned}
$$

The first term of (B.7) represents the expected surplus from Bertrand competition under secrecy, while the second term represents the expected surplus from Bertrand competition with patenting.

\section{B.4.1 Mode of Competition}

A switch from Bertrand competition to Cournot competition changes the diffusion of technology in the industry. The difference in technology diffusion is most pronounced when the goods are homogeneous (i.e., $\beta=1$ ). In such a market the consumer surplus simplifies to: $S(\mathbf{q})=U(\mathbf{q} ; \omega)-\sum_{\ell} P_{\ell}(\mathbf{q}) q_{\ell}-\omega=\frac{1}{2}\left(\sum_{\ell} q_{\ell}\right)^{2}$. If patent protection is imperfect $(\gamma<1)$, then firm $I$ has no incentive to patent its technology $\theta_{I}$ under Bertrand competition (i.e., $\theta^{b}=\bar{\theta}$ in 3.8), since it prefers not to share the market with firms $1, . ., N$. Consequently, for any $\gamma<1$ the expected consumer surplus equals:

$$
C S^{b}(\gamma)=\frac{1}{2}(\alpha-\bar{\theta})^{2}
$$

By contrast, under Cournot competition firms choose accommodating strategies, and Proposition 6 applies, as long as the market is big enough (i.e., the demand intercept $\alpha$ is sufficiently high). Suppose this is the case. For sufficiently high validity probabilities (e.g. $\gamma \geq \frac{3}{4}$ ) firm $I$ patents any technology in equilibrium. For those cases the expected consumer surplus equals:

$C S^{c}(\gamma)=\frac{1}{2} E\left\{\gamma\left[q^{c}\left(\theta_{I}, N \bar{\theta}\right)+N q^{c}\left(\bar{\theta},(N-1) \bar{\theta}+\theta_{I}\right)\right]^{2}+(1-\gamma)\left[(N+1) q^{c}\left(\theta_{I}, N \theta_{I}\right)\right]^{2}\right\}$ 
The condition under which the expected consumer surplus under Cournot competition exceeds the surplus under Bertrand competition (i.e., $C S^{c}(\gamma) \geq C S^{b}(\gamma)$ ) is equivalent to $\gamma \leq \min \left\{\gamma^{*}, 1\right\}$, with:

$$
\gamma^{*} \equiv \frac{E\left\{\left(\alpha-\theta_{I}\right)^{2}\right\}-\left(\frac{N+2}{N+1}\right)^{2}(\alpha-\bar{\theta})^{2}}{E\left\{\left(\alpha-\theta_{I}\right)^{2}\right\}-E\left\{\left(\alpha-\bar{\theta}+\frac{\bar{\theta}-\theta_{I}}{N+1}\right)^{2}\right\}}
$$

Comparison of the critical value $\gamma^{*}$ with the value $\gamma^{o}$ gives feasibility of $\gamma^{o}<\gamma<$ $\min \left\{\gamma^{*}, 1\right\}$ for some particular model specifications.

Proposition 9 If goods are homogeneous $(\beta=1)$, the market is sufficiently small ( $\alpha$ close to $2 \bar{\theta}-\underline{\theta})$, and the technology distribution is sufficiently skewed ( $E\left\{\theta_{I}\right\}$ close to $\underline{\theta})$, then the critical protection parameter $\gamma^{c}$ exists, with $\gamma^{o}<\gamma^{c} \leq 1$, such that: $C S^{c}(\gamma)>C S^{b}(\gamma)$ for all $\gamma^{o}<\gamma<\gamma^{c}$.

Proof of Proposition 9 Substitution of (4.5) in (B.9) gives:

$$
C S^{c}(\gamma)=\frac{1}{2} E\left\{\gamma\left[\frac{1}{N+2}\left((N+1) \alpha-\theta_{I}-N \bar{\theta}\right)\right]^{2}+(1-\gamma)\left[\frac{N+1}{N+2}\left(\alpha-\theta_{I}\right)\right]^{2}\right\}
$$

Using (B.8) and (B.11), it is easy to reduce the inequality $C S^{c}(\gamma) \geq C S^{b}(\gamma)$ to $\gamma \leq \gamma^{*}$, with $\gamma^{*}$ as in (B.10). The critical protection probability (B.10) can be rewritten as:

$\gamma^{*}=1+\frac{\left(\bar{\theta}-E\left\{\theta_{I}\right\}\right)\left[2(N+1) \alpha-(2 N+1) \bar{\theta}-E\left\{\theta_{I}\right\}\right]+\operatorname{var}\left\{\theta_{I}\right\}-(2 N+3)(\alpha-\bar{\theta})^{2}}{N\left(\bar{\theta}-E\left\{\theta_{I}\right\}\right)\left[2(N+1) \alpha-N \bar{\theta}-(N+2) E\left\{\theta_{I}\right\}\right]+N(N+2) \operatorname{var}\left\{\theta_{I}\right\}}$

For $\alpha=2 \bar{\theta}-\underline{\theta}$ this reduces to:

$\gamma^{*}=1+\frac{\left(\bar{\theta}-E\left\{\theta_{I}\right\}\right)\left[(2 N+3)(\bar{\theta}-\underline{\theta})-\left(E\left\{\theta_{I}\right\}-\underline{\theta}\right)\right]+\operatorname{var}\left\{\theta_{I}\right\}-(2 N+3)(\bar{\theta}-\underline{\theta})^{2}}{N\left(\bar{\theta}-E\left\{\theta_{I}\right\}\right)\left[(3 N+4)(\bar{\theta}-\underline{\theta})-(N+2)\left(E\left\{\theta_{I}\right\}-\underline{\theta}\right)\right]+N(N+2) \operatorname{var}\left\{\theta_{I}\right\}}$

Taking $E\left\{\theta_{I}\right\} \rightarrow \underline{\theta}$, this gives:

$$
\gamma^{*} \rightarrow 1+\frac{\operatorname{var}\left\{\theta_{I}\right\}}{N(3 N+4)(\bar{\theta}-\underline{\theta})^{2}+N(N+2) \operatorname{var}\left\{\theta_{I}\right\}}
$$

which exceeds 1 . For any $\alpha \geq 2 \bar{\theta}-\underline{\theta}$, the critical probability $\gamma^{o}$ in (4.7) is such that $\lim _{E\left\{\theta_{I}\right\} \rightarrow \underline{\theta}} \gamma^{o}=1$, and $\gamma^{o}<1$ for all $E\left\{\theta_{I}\right\}>\underline{\theta}$. Hence, for $\alpha=2 \bar{\theta}-\underline{\theta}, \lim _{E\left\{\theta_{I}\right\} \rightarrow \underline{\theta}}\left(\gamma^{*}-\gamma^{o}\right)>$ 0 , and continuity of $\gamma^{*}-\gamma^{o}$ in $E\left\{\theta_{I}\right\}$ gives the existence of $\gamma^{c} \equiv \min \left\{\gamma^{*}, 1\right\}>\gamma^{o}$ for 
some small mean $E\left\{\theta_{I}\right\}>\underline{\theta}$. Further, a slightly higher $\alpha$ gives similar results, again due to continuity.

In other words, there are model specifications such that strategic patenting reverses the typical surplus ranking of Cournot and Bertrand competition. The intuition for this result is as follows. First, a low demand intercept (i.e., $\alpha$ is sufficiently close to $2 \bar{\theta}-\underline{\theta}$ ) keeps the price low under Cournot competition, while it does not affect the price under Bertrand competition. Second, the expected knowledge spillover under Cournot competition is the highest for low $E\left\{\theta_{I}\right\}$ and low $\gamma$. The high level of expected technology diffusion increases expected consumer surplus under Cournot competition. Further, a high variance of $\theta_{I}$ is also favorable for the reversal of the ranking, since it creates a high output variance under Cournot competition, which increases the expected consumer surplus.

Figure 5 illustrates the expected consumer surplus comparison under the conditions of Proposition 9. The thin flat line represents the consumer surplus under

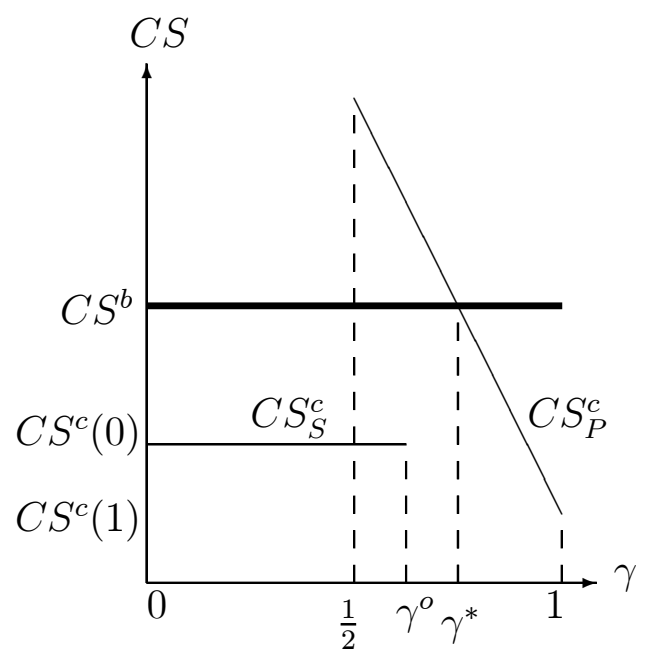

Figure 5: Consumer surplus (Bertrand vs. Cournot)

Cournot competition, when firm $I$ keeps its innovation secret (i.e., for $\gamma \leq \gamma^{o}$ ). The thin downward-sloping line represents the consumer surplus under Cournot competition when firm $I$ patents all technologies (i.e., for $\gamma \geq \frac{1}{2}$ ). The bold flat line represents the expected consumer surplus under Bertrand competition. First, in the absence of expropriation, information sharing gives a lower consumer surplus than information concealment when firms compete in quantities (Shapiro, 1986): $C S^{c}(1)<C S^{c}(0)$ as Figure 5 illustrates. This property is related to Proposition 10. Second, given secrecy, Bertrand competition gives a higher expected surplus than Cournot competition 
(Singh and Vives, 1984): $C S^{c}(0)<C S^{b}$. Finally, given full patenting and Cournot competition, a reduction of the patent validity parameter from perfect protection increases the expected surplus due to increased technology diffusion.

\section{B.4.2 Patent Policy}

Consider a consumer surplus-maximizing economic policy maker who can affect the value of the patent validity, $\gamma$, in a market with sufficiently differentiated goods. The expected consumer surplus (B.7) depends as follows on the patent validity:

$$
\begin{aligned}
d C S^{b}(\gamma) / d \gamma= & {\left[1-F\left(\theta^{b}\right)\right] E\left\{S^{b}\left(\theta_{I}, \bar{\theta}\right)-S^{b}\left(\theta_{I}, \theta_{I}\right) \mid \theta_{I}>\theta^{b}\right\} } \\
& +\frac{\partial \theta^{b}}{\partial \gamma} f\left(\theta^{b}\right)\left(S^{B}\left(\theta^{b} ; E\left\{\theta_{I} \mid \theta_{I} \leq \theta^{b}\right\}\right)-\gamma S^{b}\left(\theta^{b}, \bar{\theta}\right)-(1-\gamma) S^{b}\left(\theta^{b}, \theta^{b}\right)\right) \\
& +\frac{\partial \theta^{b}}{\partial \gamma} F\left(\theta^{b}\right) E\left\{\frac{\partial S^{B}\left(\theta_{I} ; E\left\{\theta_{I} \mid \theta_{I} \leq \theta^{b}\right\}\right)}{\partial \theta^{b}} \mid \theta_{I} \leq \theta^{b}\right\}
\end{aligned}
$$

This expression captures the following effects. On the one hand, an increase of the probability $\gamma$ reduces the likelihood of expropriation of patented technologies. In other words, welfare-enhancing technology transfers from firm $I$ to firms $1, . ., N$ become less likely. This direct effect, which is captured by the first term of expression (B.12), is negative. On the other hand, increasing the probability of patent validity has an indirect effect through a change of the equilibrium patenting strategy. Increasing the probability of validity implies that more technologies are patented (i.e., $\theta^{b}$ decreases). First, this increases the expected welfare at the margin, since it replaces the expected welfare under secrecy by the expected welfare under patenting. This positive effect is captured in the second term of (B.12). Second, reducing $\theta^{b}$ changes the equilibrium beliefs of firms $1, . ., N$ after the adoption of secrecy. In particular, after a reduction of $\theta^{b}$ the non-innovative firms expect a more efficient competitor in the product market, which reduces equilibrium prices under secrecy. This positive effect is captured by the third term of (B.12). The optimal patenting policy resolves the trade-off between these effects.

The comparison of the expected consumer surplus for perfect patent protection $(\gamma=1)$ and no patent protection $(\gamma=0)$ reduces to the surplus comparison between information sharing and selective patenting. First, for technologies that are shared in the absence of patent protection, prices are lower without protection, due to the diffusion of technology in this case. Second, for technologies that are kept secret in the absence of patent protection the consumers are on average better off without patent protection, since output levels have a greater variance under secrecy, which 
yields a quantity adjustment effect there (e.g. Vives, 1999). Both effects give a higher expected surplus under no protection.

Proposition 10 Perfect intellectual property protection yields a lower expected consumer surplus than no protection, i.e., $C S^{b}(1)<C S^{b}(0)$. Moreover, a reduction of the patent validity from perfect protection increases the expected consumer surplus initially, i.e., $d C S^{b}(1) / d \gamma<0$.

Proof of Proposition 10 Expression (B.7) gives:

$$
\begin{aligned}
C S^{b}(0)-C S^{b}(1)= & F\left(\theta_{0}\right) E\left\{S^{B}\left(\theta_{I} ; E\left\{\theta_{I} \mid \theta_{I} \leq \theta_{0}\right\}\right)-S^{b}\left(\theta_{I}, \bar{\theta}\right) \mid \theta_{I} \leq \theta_{0}\right\} \\
& +\left[1-F\left(\theta_{0}\right)\right] E\left\{S^{b}\left(\theta_{I}, \theta_{I}\right)-S^{b}\left(\theta_{I}, \bar{\theta}\right) \mid \theta_{I}>\theta_{0}\right\}
\end{aligned}
$$

where $\theta_{0} \equiv \lim _{\gamma \rightarrow 0} \theta^{b}$. It is straightforward to show that

$$
E\left\{S^{B}\left(\theta_{I} ; E\left\{\theta_{I} \mid \theta_{I} \leq \theta_{0}\right\}\right)-S^{b}\left(\theta_{I}, \bar{\theta}\right) \mid \theta_{I} \leq \theta_{0}\right\}=\frac{5 \beta^{2}\left(2-\beta^{2}\right)}{4\left(4-\beta^{2}\right)^{2}\left(1-\beta^{2}\right)^{2}} \operatorname{Var}\left\{\theta_{I} \mid \theta_{I} \leq \theta_{0}\right\}>0 .
$$

Moreover, $S^{b}\left(\theta_{I}, \theta_{I}\right)>S^{b}\left(\theta_{I}, \bar{\theta}\right)$ for any $\theta_{I}<\bar{\theta}$, if $\beta$ is sufficiently small (such that firm $I$ has no incentive to set a limit price). Hence, $C S^{b}(0)>C S^{b}(1)$.

Finally, $d C S^{b}(1) / d \gamma=E\left\{S^{b}\left(\theta_{I}, \bar{\theta}\right)-S^{b}\left(\theta_{I}, \theta_{I}\right)\right\}<0$, since $\lim _{\gamma \rightarrow 1} \theta^{b}=\underline{\theta}$.

Finally, there may exist intermediate patent validity parameter values $(0<\gamma<1)$ that generate a higher expected consumer surplus than under no patent protection. Figure 6 illustrates the expected surplus under Bertrand competition for a uniformly distributed technology parameter $\theta_{I}$.

The relation between the protection parameter and consumer surplus is similar for firms that compete in quantities (Cournot competition). ${ }^{18}$

\footnotetext{
${ }^{18}$ Under Cournot competition the comparison of the expected consumer surplus for perfect patent protection $(\gamma=1)$ and no patent protection $(\gamma=0)$ reduces to the surplus comparison between information sharing and information concealment. The consumers are on average better off without patent protection than with perfect patent protection, since the expected consumer surplus from information concealment exceeds the surplus from information sharing (Shapiro, 1986).
} 


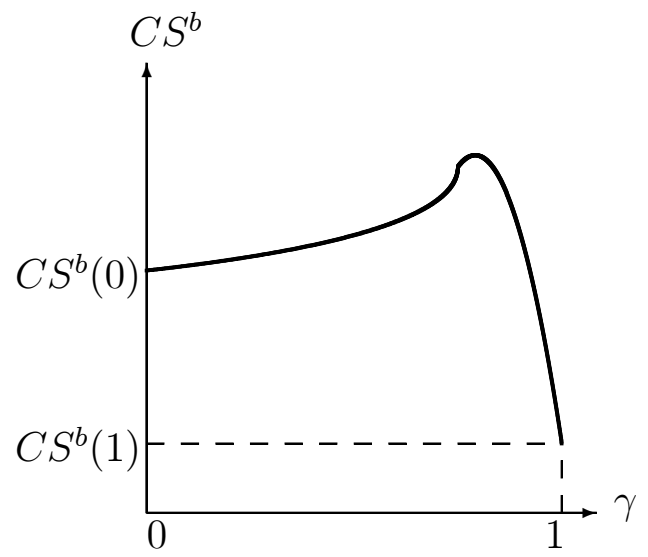

Figure 6: Consumer surplus (uniform distribution)

\section{References}

Allen, R.C. (1983) "Collective Invention", Journal of Economic Behavior and Organization 4, 1-24

Anton, J.J. And Yao, D.A. (2003) "Patents, Invalidity, and the Strategic Transmission of Enabling Information", Journal of Economics and Management Strategy $12,151-78$

Anton, J.J. And YAo, D.A. (2004) "Little Patents and Big Secrets: Managing Intellectual Property", RAND Journal of Economics 35 (1), 1-22

Belleflamme, P. and Vergari, C. (2006) "Incentives to Innovate in Oligopolies", CORE Discussion Paper 2006/14

Boone, J. (2000) "Competitive Pressure: The Effects on Investments in Product and Process Innovation", RAND Journal of Economics 31, 549-569

Cohen, W.M., Nelson, R.R. And Walsh, J.P. (2000) "Protecting Their Intellectual Assets: Appropriability Conditions and Why U.S. Manufacturing Firms Patent (or Not)", NBER Working Paper nr. 7552

De Fraja, G. (1993) "Strategic Spillovers in Patent Races", International Journal of Industrial Organization 11, 139-146

Dixit, A. (1979) "A Model of Duopoly Suggesting a Theory of Entry Barriers", The Bell Journal of Economics 10, 20-32 
Fosfuri, A. And Rønde, T. (2004) "High-Tech Clusters, Technology Spillovers, and Trade Secret Laws", International Journal of Industrial Organization 22, 45-65

GaL-Or, E. (1986) "Information Transmission - Cournot and Bertrand Equilibria", Review of Economic Studies 53, 85-92

Gersbach, H. and Schmutzler, A. (2003) "Endogenous Technological Spillovers: Causes and Consequences", Journal of Economics \&3 Management Strategy 12, 197205

Gilbert, E. (2006) "Looking for Mr. Schumpeter: Where Are We in the CompetitionInnovation Debate?", in Jaffe, A.B., Lerner, J., and Stern, S. (ed.) Innovation Policy and the Economy, Vol. 6, Cambridge MA, MIT Press, 159-215

Gill, D. (2008) "Strategic Disclosure of Intermediate Research Results", Journal of Economics 83 Management Strategy 17, 733-758

Grossman, S.J. (1981) "The Informational Role of Warranties and Private Disclosure about Product Quality", Journal of Law and Economics 24, 461-483

Jansen, J. (2006) "The Effects of Disclosure Regulation of an Innovative Firm" in Choi, J.P. (ed.) Recent Developments in Antitrust: Theory and Evidence, Cambridge MA, MIT Press, 265-291

Jansen, J. (2009) "Share To Scare: Technology Sharing in the Absence of Intellectual Property Rights", mimeo, Max Planck Institute for Research on Collective Goods, Bonn

Kamien, M.I. And Zang, I. (2000) "Meet Me Halfway: Research Joint Ventures and Absorptive Capacity", International Journal of Industrial Organization 18, 995-1012

Katsoulacos, Y. and Ulph, D. (1998) "Endogenous Spillovers and the Performance of Research Joint Ventures", Journal of Industrial Economics 46, 333-357

Lemley, M.A. and Shapiro, C. (2005) "Probabilistic Patents", Journal of Economic Perspectives 19, 75-98

Levin, R., Klevorick, A., Nelson, R.R. and Winter, S.G. (1987) "Appropriating the Returns from Industrial R\&D", Brookings Papers on Economic Activity, $783-820$ 
Milgrom, P.R. (1981) "Good News and Bad News: Representation Theorems and Applications", Bell Journal of Economics 12, 380-91

Milgrom, P.R. And Roberts, J. (1986) "Relying on the Information of Interested Parties", RAND Journal of Economics 17, 18-32

Milliou, C. (2009) "Endogenous Protection of R\&D Investments", Canadian Journal of Economics 42, 184-205

Nuvolari, A. (2004) "Collective Invention During The British Industrial Revolution: the Case of the Cornish Pumping Engine", Cambridge Journal of Economics 28, 347363

Okuno-Fujiwara, M., Postlewaite, A., and Suzumura, K. (1990) "Strategic Information Revelation", Review of Economic Studies 57, 25-47

Shapiro, C. (1986) "Exchange of Cost Information in Oligopoly", Review of Economic Studies 53, 433-446

Shapley, L. And Shubik, M. (1969) "Price Strategy Oligopoly with Product Differentiation", Kyklos 22, 30-44.

Singh, N. And Vives, X. (1984) "Price and Quantity Competition in a Differentiated Duopoly", RAND Journal of Economics 15, 546-554

Vives, X. (2008) "Innovation and Competitive Pressure", Journal of Industrial Economics 56, 419-469 